\title{
Antidiabetic therapies and male reproductive function: where do we stand?
}

\author{
R S Tavares ${ }^{1,4}$, S Escada-Rebelo ${ }^{1,2}$, A F Silva1, M I Sousa1, J Ramalho-Santos ${ }^{1,3}$ and S Amaral ${ }^{1,4}$ \\ ${ }^{1}$ Biology of Reproduction and Stem Cell Group, CNC-Center for Neuroscience and Cell Biology, University of \\ Coimbra, Coimbra, Portugal, ${ }^{2}$ PhD Programme in Experimental Biology and Biomedicine, CNC, Coimbra, Portugal, \\ ${ }^{3}$ Department of Life Sciences, University of Coimbra, Coimbra, Portugal and ${ }^{4}$ Institute for Interdisciplinary Research, \\ University of Coimbra, Coimbra, Portugal
}

Correspondence should be addressed to S Amaral; Email: scgamaral@gmail.com

*(R S Tavares, S Escada-Rebelo, A F Silva and M I Sousa contributed equally to this work and should be considered joint first authors)

\begin{abstract}
Diabetes mellitus has been increasing at alarming rates in recent years, thus jeopardizing human health worldwide. Several antidiabetic drugs have been introduced in the market to manage glycemic levels, and proven effective in avoiding, minimizing or preventing the appearance or development of diabetes mellitus-related complications. However, and despite the established association between such pathology and male reproductive dysfunction, the influence of these therapeutic interventions on such topics have been scarcely explored. Importantly, this pathology may contribute toward the global decline in male fertility, giving the increasing preponderance of diabetes mellitus in young men at their reproductive age. Therefore, it is mandatory that the reproductive health of diabetic individuals is maintained during the antidiabetic treatment. With this in mind, we have gathered the available information and made a critical analysis regarding the effects of several antidiabetic drugs on male reproductive function. Unlike insulin, which has a clear and fundamental role on male reproductive function, the other antidiabetic therapies' effects at this level seem incoherent. In fact, studies are highly controversial possibly due to the different experimental study approaches, which, in our opinion, suggests caution when it comes to prescribing such drugs to young diabetic patients. Overall, much is still to be determined and further studies are needed to clarify the safety of these antidiabetic strategies on male reproductive system. Aspects such as the effects of insulin levels variations, consequent of insulin therapy, as well as what will be the impact of the side effect hypoglycemia, common to several therapeutic strategies discussed, on the male reproductive system are still to be addressed.

Reproduction (2018) 155 R13-R37
\end{abstract}

\section{Diabetes, antidiabetic drugs and male reproductive function}

Diabetes mellitus is a global epidemic that currently affects over 400 million adults worldwide and it is predicted to raise to over 600 million in 2040 (IDF 2015, WHO 2016). This is a complex metabolic systemic disease characterized by hyperglycemia, that results from impaired insulin action and/or secretion, being the main cause of micro and macro vascular pathologies and one of the leading causes of morbidity and mortality (Alberti \& Zimmet 1998, Emilien et al. 1999, Roglic et al. 2005), contributing to 5 million annual deaths worldwide, ultimately having a devastating human, social and economic impact (IDF 2015, WHO 2016).

The principal forms of this disease are type 1 and type 2 , the first being caused by the immune destruction of $\beta$-pancreatic cells and lack of insulin production while the second, the more prevalent form, is characterized by insulin resistance and inappropriate insulin secretory response (Alberti \& Zimmet 1998, ADA 2016b). Although genetic and independent accelerating factors might have a role, hyperglycemia is recognized as one of the main perpetrators of the disease-induced complications, through the activation of a variety of damage pathways that seem to be triggered by mitochondrial superoxide overproduction (TDC\&CTRG 1993, Brownlee 2005), emphasizing the role of oxidative stress in the development of clinical complications associated with the disease (Ahmed 2005, Pitocco et al. 2010). However, due the complexity of the disease, we cannot exclude that other players might also be involved in the pathophysiology of the disease (Greenfield \& Campbell 2006, Muoio \& Newgard 2008).

Not surprisingly, all the levels of the male reproductive system seem to be a target for the deleterious effects of diabetes. In fact, this degenerative disease was described to affect not only sperm quality and function 
(Bartak et al. 1975, Padron et al. 1984, Handelsman et al. 1985, Vignon et al. 1991, Baccetti et al. 2002, Soudamani et al. 2005, Amaral et al. 2006, Scarano et al. 2006, Agbaje et al. 2007, Delfino et al. 2007, Shrilatha \& Muralidhara 2007a, Rama Raju et al. 2012, Roessner et al. 2012, Schoeller et al. 2012a, Mangoli et al. 2013) but also the hypothalamus-pituitary-gonadal axis (HPG) (Benitez \& Perez Diaz 1985, Seethalakshmi et al. 1987, Sudha et al. 2000, Baccetti et al. 2002, Lopez-Alvarenga et al. 2002, Ballester et al. 2004, Kim \& Moley 2008, Schoeller et al. 2012b), the testicular function and spermatogenesis (Cameron et al. 1985, Gondos \& Bevier 1995, Sanguinetti et al. 1995, Sainio-Pollanen et al. 1997, Ballester et al. 2004, Arikawe et al. 2006, Amaral et al. 2009, Kianifard et al. 2012, Schoeller et al. 2012b, Wankeu-Nya et al. 2013, Kyathanahalli et al. 2014, Tavares et al. 2016), the accessory organs (epididymis, prostate and seminal vesicles) (Murray et al. 1981, Fukumoto et al. 1993, Ikeda et al. 2000, Saito et al. 2000, Soudamani et al. 2005, Morrison et al. 2006, Singh et al. 2009, La Vignera et al. 2011) and both erectile and ejaculatory function (Penson et al. 2009). Nonetheless, some controversy exists in the literature regarding this topic, and there are also some studies that reported no significant modifications or changes only in some of the aspects (Niven et al. 1995, NavarroCasado et al. 2010, La Vignera et al. 2015). These different reports might be related to aspects that varied among studies, such as duration of the disease, type of glycemic control, patient and animal model selection, experimental design and technical approaches.

Although it is not entirely understood how the reproductive impairment in males is orchestrated, recent reports showed that fertility in diabetic males and animal models is impaired (Ballester et al. 2004, Kim \& Moley 2008, Bener et al. 2009, La Vignera et al. 2009a) and that diabetic patients frequently seek for fertility treatments, pregnancy rates being reduced in couples in whom the male is diabetic (Mulholland et al. 2011). Such evidence further supports that something is wrong in the reproductive potential of these patients and that alterations at several levels of the male reproductive system might have happened. Additionally, this also stresses the importance of monitoring diabetic patients' reproductive health, mainly because the epidemic rise of the disease is affecting more and more men, and worryingly, at the acme of their reproductive phase (Agbaje et al. 2007), which might compromise the likelihood of fathering a child.

It is widely accepted that good management of diabetes, namely the glycemic control, is a key component to minimize, avoid or prevent diabetic complications (TDC\&CTRG 1993, El-Kaissi \& Sherbeeni 2011, ADA 2016c). At the male reproductive level, this is also a quite pertinent issue considering that: (1) glucose was reported to be at higher levels in the semen of diabetic patients (Padron et al. 1984) raising the question whether hyperglycemia, besides the systemic effects, may also contribute toward the alterations observed in diabetic patients' sperm; (2) a poor metabolic/glycemic control was negatively associated not only with sperm parameters (Padron et al. 1984, La Vignera et al. 2009b, 2015, Roessner et al. 2012) but also with other reproductive features (Ahn et al. 2007, La Vignera et al. 2011, Choi et al. 2015), though some studies did not find any relation (Niven et al. 1995). In this way, another essential question arises: how will the antidiabetic drugs impact the male reproductive function? Though habitually overlooked, considering the epidemic raise of diabetes and its high prevalence in young males, this constitutes a crucial point, as it is important to guarantee the reproductive health of diabetic individuals during antidiabetic treatments. To address this pertinent subject, we critically analyzed the existing literature focused on the effects of several antidiabetic strategies on various aspects of the male reproductive system (Table 1).

Currently, there is a large variety of antidiabetic therapies available, which although varying in the mechanisms of action, efficacy, side effects and cost, have the same purpose, that is to control blood glucose levels (El-Kaissi \& Sherbeeni 2011, ADA 2016d). Although for type 1 diabetic patients, insulin therapy is indispensable, the basis of primary management for type 2 patients entails lifestyle modifications along with metformin treatment (El-Kaissi \& Sherbeeni 2011, ADA 2016d). Moreover, for type 2 diabetes, other treatments exist, such as sulphonylureas, meglitidines, insulin and thiazolidinediones/glitazones. However, as these therapeutic options are associated with weight gain and/or hypoglycemia and increase risk of cardiac and kidney disease (El-Kaissi \& Sherbeeni 2011, ADA 2016d, Skliros et al. 2016), alternative therapies were developed to overcome these problems as it is the case of $\alpha$-glucosidase inhibitors, glucagon-like peptide- 1 agonists, dipeptidyl peptidase-IV (DPP-4) inhibitors, sodium-glucose transporter 2 (SGLT2) inhibitors, amylin analogues and bile acid sequestrants. These pharmaceuticals can also be used in combination in some cases (El-Kaissi \& Sherbeeni 2011, ADA 2016d). However, the optimal approach form of glycemic control should be patient-tailored, having in consideration the existence of comorbidities and side effects (El-Kaissi \& Sherbeeni 2011, ADA 2016a). Nonetheless, their impact on male reproductive function is not fully disclosed.

\section{Insulin}

Being secreted by the $\beta$-pancreatic cells after nutrient ingestion, insulin constitutes the earliest introduced treatment for diabetes, discovered back in the 1920s (Shabanpoor et al. 2009, El-Kaissi \& Sherbeeni 2011, Zhang \& Liu 2014). Worth mentioning, more is known about the effects of this drug on the male reproductive function, mainly because this hormone 


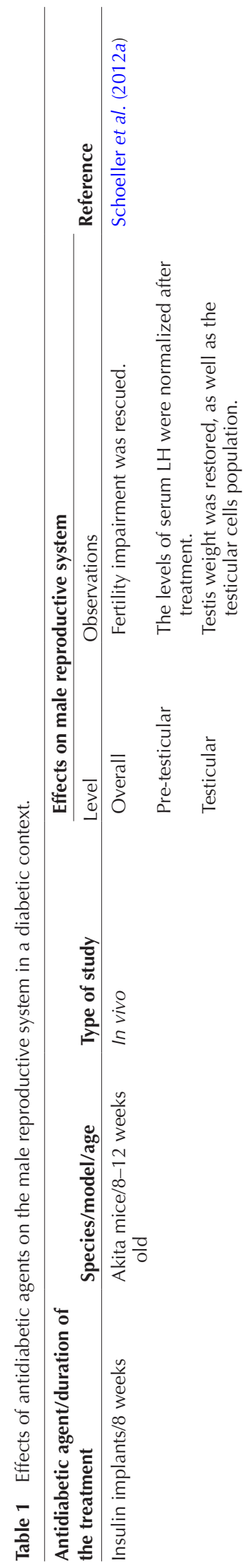

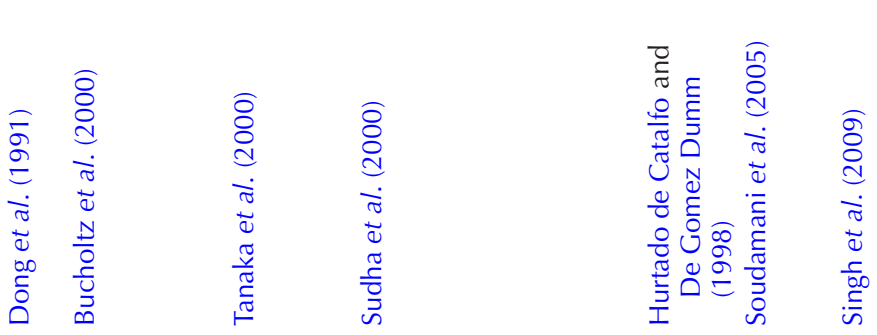

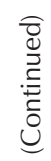

\section{II}

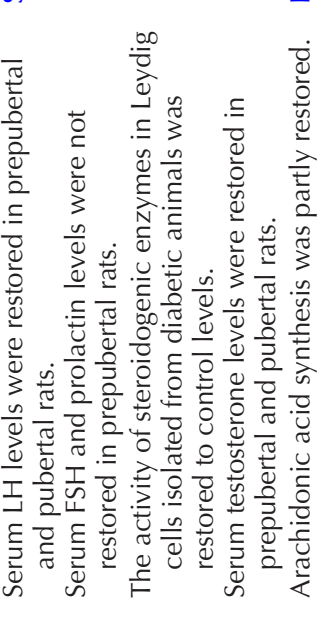

产

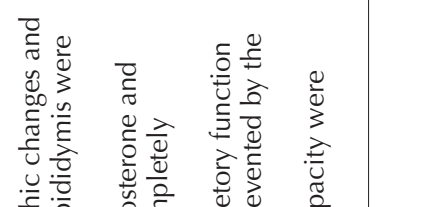

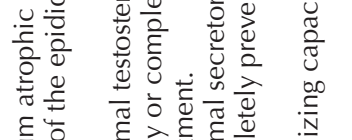

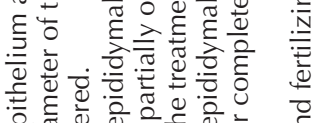

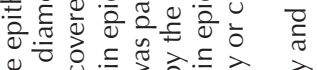

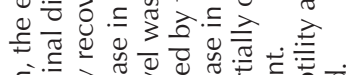

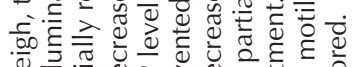

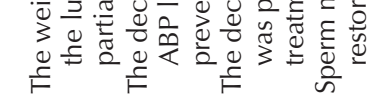

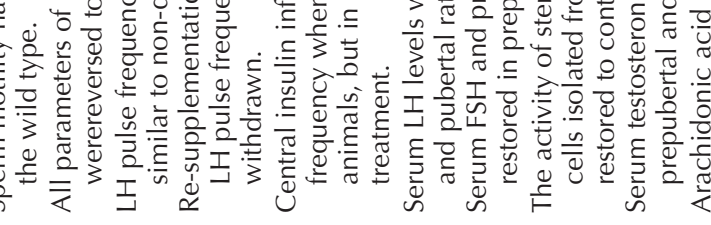




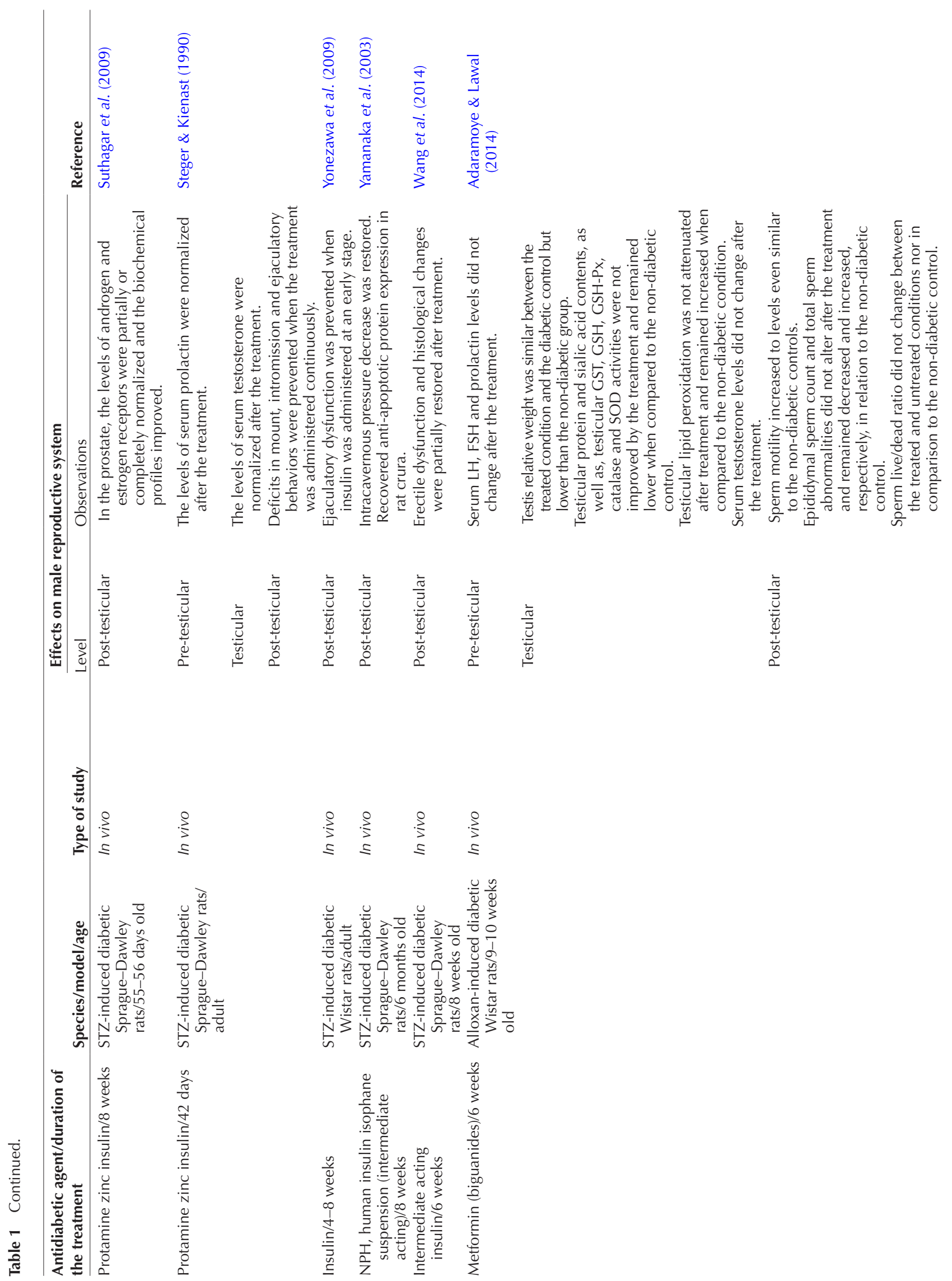



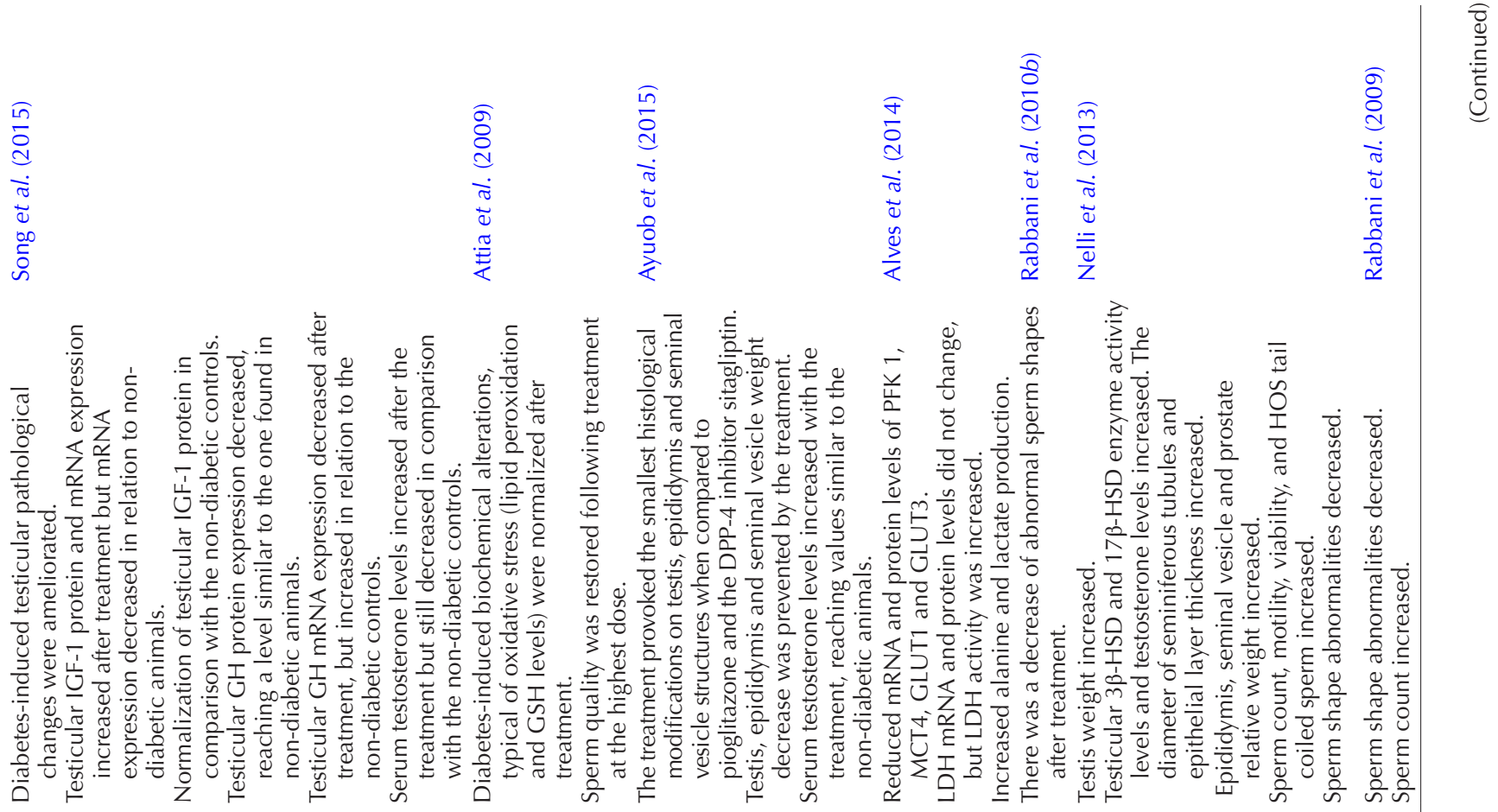

$\frac{\frac{\pi}{2}}{\frac{\pi}{2}}$
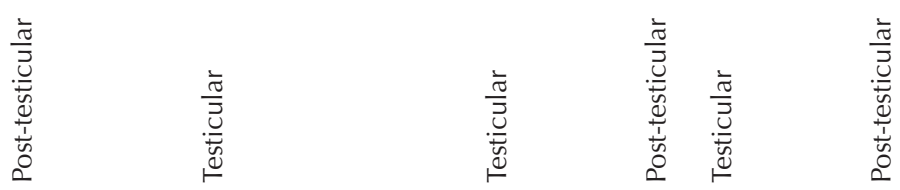

$\frac{1}{J}$
$\frac{U}{4}$
$\frac{d}{1}$
$\frac{1}{0}$
0

$\stackrel{\frac{5}{3}}{\frac{1}{3}}$

$\begin{array}{ll}\stackrel{2}{3} & \stackrel{2}{3} \\ 0 & \stackrel{2}{3}\end{array}$

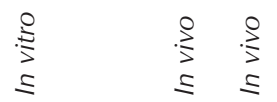

$\stackrel{\frac{1}{3}}{3}$

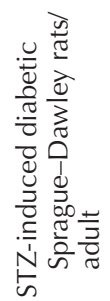
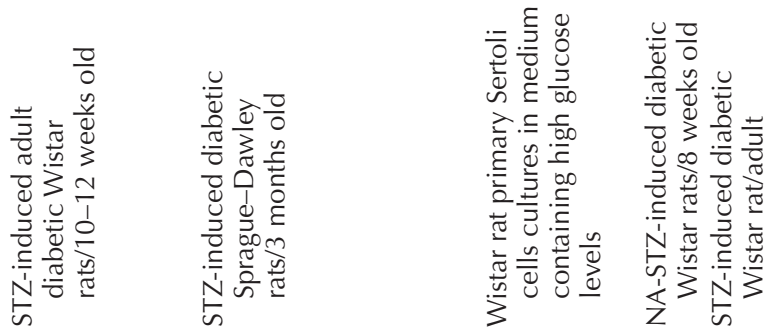

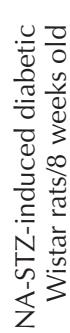

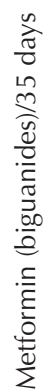

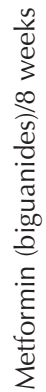

$\frac{0}{0}$
0
0
0
$\frac{0}{0}$
$\frac{0}{0}$
$\frac{0}{5}$
$\frac{00}{0}$
0
$\frac{5}{6}$
$\frac{1}{0}$
0
$\frac{0}{2}$
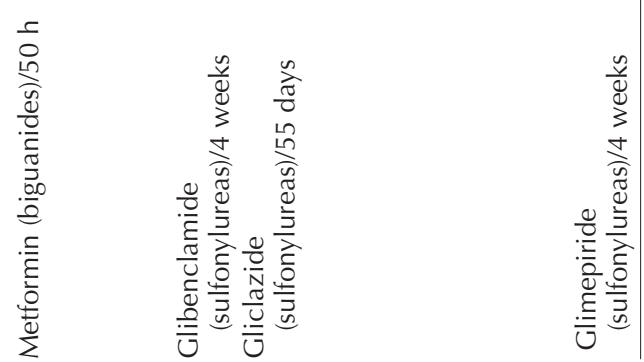

www.reproduction-online.org 


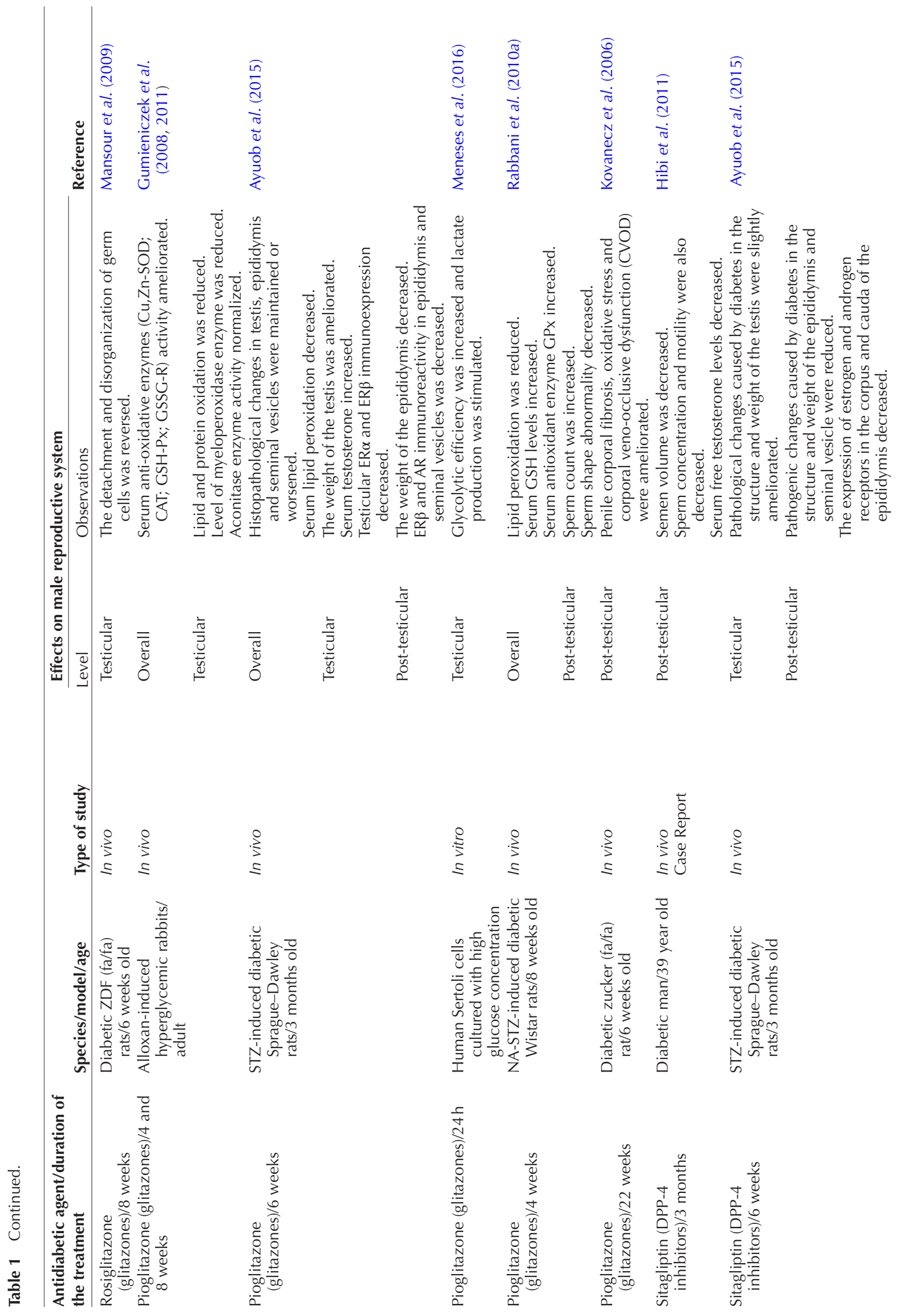

www.reproduction-online.org 


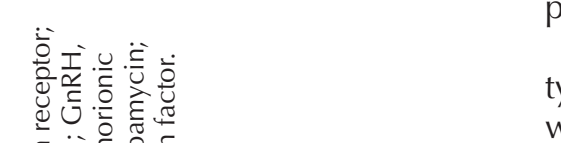

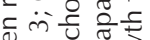

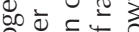

은

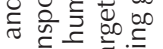

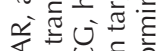

is

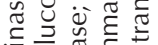

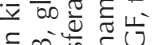

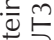

is normally present in the body and is crucial for physiological homeostasis.

Though insulin therapy is imperative for patients with type 1 diabetes and might also be used by some patients with type 2 diabetes in more advanced stages of the disease, this therapy has been frequently associated with the occurrence of hypoglycemia that, if not managed appropriately, might have severe consequences that can ultimately lead to mortality (Cryer 2008).

The insulin signaling network is rather complex and its activation is dependent on the insulin binding to its receptors and recruitment of insulin receptor substrate, followed by the activation of two key signaling pathways, the phosphatidylinositol-3-kinase (PI3K) pathway and the mitogen-activated protein kinase pathway, through which insulin will accomplish its functions regulating a panoply of processes (Zhang \& Liu 2014). Besides the role of insulin in glucose disposal, this hormone is also involved in the modulation of other processes such as cellular growth, proliferation differentiation and survival (Zhang \& Liu 2014).

Importantly, as the energy stores need to be managed properly to assure physiological function, a close relationship exists between insulin signaling and fertility (Porte et al. 2005, Mauvais-Jarvis 2016), raising the question on how insulin-deregulated action and levels oscillation occurring not only during the time course of the disease (hyperinsulinemia/hypoinsulinemia), but also during therapy (hyperinsulinemia), will influence male reproductive function.

\section{Insulin and male reproductive function}

The interest on the insulin effects on the male reproductive function is well mirrored by the numerous reports found in the literature. In fact, insulin action is extended to all the levels of the male reproductive system, from the HPG to the testis, also having a role in male accessory organs, erectile and ejaculatory function and ultimately on sperm, as we will discuss in the following sections.

Insulin was shown to interfere with the HPG axis, stimulating $\mathrm{LH}$ and $\mathrm{FSH}$ release in pituitary cell cultures (Adashi et al. 1981) and GnRH secretion and expression in hypothalamic neurons in culture (Burcelin et al. 2003). Furthermore, the brain-specific KO for insulin receptor resulted in male mice with decreased fertility. Alterations such as reduction in offspring, impaired spermatogenesis, decline in epididymal sperm content and decrease in Leydig cells population and in serum LH have been reported, suggesting a role for insulin in the brain hormonal output, and consequences of its absence at the testicular level, compromising spermatogenesis' outcome (Bruning et al. 2000).

However, insulin might also act directly in the testis. In fact, insulin receptors as well as insulin expression has been described in the testis, pointing to an important role of insulin in spermatogenesis regulation 
(Saucier et al. 1981, Gomez et al. 2009). It is therefore logical to hypothesize that the insulin variations that occur during diabetes might affect insulin signaling at the testis level, potentially affecting spermatogenesis.

Although the cellular complexity of the testis might complicate the understanding of insulin signaling in this organ, evidence is now available regarding almost all the cell types that participate in the spermatogenesis, namely germ and the somatic Sertoli and Leydig cells.

At the Sertoli cell level, in vitro studies have shown that insulin-stimulated androgen-binding protein $(A B P)$ secretion, which is an indicator of Sertoli cell function (Karl \& Griswold 1980). Additionally, insulin was reported to have positive effects on DNA and protein synthesis (Borland et al. 1984) and on lactate (Borland et al. 1984, Oonk et al. 1985) and transferrin secretion (Skinner \& Griswold 1982) in cultured rat Sertoli cells. Later on, insulin receptors were identified in Sertoli cells (Oonk \& Grootegoed 1987), suggesting that the effects of insulin on these cells were receptor-mediated and that insulin has a determinant role on Sertoli cells metabolism and function, which might have consequences in terms of spermatogenesis. In fact, subsequent studies support this hypothesis with several metabolic alterations being reported when human Sertoli cells were cultured in the absence of insulin (Alves et al. 2012, Oliveira et al. 2012). Moreover, the authors further investigated this issue describing that insulin deprivation led to a deregulation in the apoptotic signaling in rat Sertoli cells (Dias et al. 2013). The authors suggested that these alterations might compromise spermatogenesis and contribute to the adverse effects of type 1 diabetes, and its typical insulin deficiency, on male reproductive system (Alves et al. 2012, Oliveira et al. 2012, Dias et al. 2013).

Insulin receptors are also reported in Leydig cells (Lin et al. 1986), and insulin was described to have a role on these cells' growth and proliferation (Khan et al. 1992). Furthermore, insulin was observed to increase testosterone production in primary Leydig cell cultures (Lin et al. 1986). Hence, insulin might exert its effects directly on Leydig cells or through its action on LH that will further regulate Leydig cell function.

Finally, there are also data to support a role of insulin on germ cells, promoting rat spermatogonial DNA synthesis and newt spermatogonia differentiation, corroborating its important role on spermatogenesis (Soder et al. 1992, Nakayama et al. 1999). However, insulin's role on the male reproductive function is not limited to the HPG and testis, and soon a role of insulin on sperm was recognized.

Early in the 1970s, insulin was described as an important regulator of sperm metabolism, as it was observed that in vitro addition of insulin to human sperm increased motility and glucose utilization, primarily through the stimulation of pentose pathway and Krebs cycle (Hicks et al. 1973). Nonetheless, the insulin's role on sperm glucose metabolism modulation was questioned by divergent observations reported some years later (Gorus \& Pipeleers 1986).

Considering that, in the female follicular fluid, insulin levels peak at the ovulation time, Silvestroni and coworkers investigated the effects of insulin on human sperm and have shown that this hormone acts at the acrosome and sperm plasma membrane, suggesting the involvement of insulin in the acrosome reaction, a process that allows sperm-oocyte binding (Silvestroni et al. 1992). In a further study regarding the effects of several hormones on rat sperm motility, intratesticular injection of insulin was shown to cause a decrease in vas deferens' sperm motility. However, when sperm were removed from the vas deferens and incubated in phosphate buffer saline in vitro, the percentage of motile sperm was observed to increase, which have led the authors to suggest that these divergent effects might be due to physiological aspects of the duct system that maintain the motility down to save energy that might be used in other processes (Sliwa 1994).

Some years later, important observations were made by Aquila and coworkers reporting that insulin is expressed and secreted in human ejaculated sperm. Furthermore, they described that both insulin secretion and glucose metabolism were regulated by insulin in an autocrine fashion and that sperm insulin secretion might have a role in capacitation, a process that confers sperm fertilizing competence. These were significant findings as they suggest that insulin might regulate sperm glucose metabolism depending on the different circumstances and needs, independently of systemic insulin (Aquila et al. 2005) and suggesting another possible way by which diabetes can interfere with sperm function (Schoeller et al. 2012b).

These results were later corroborated in pigs with the identification of insulin receptors in sperm and the description of an additional role of insulin in the acrosome reaction (Carpino et al. 2010). Accordingly, other study has reported positive effects of insulin not only on human sperm motility but also on the acrosome reaction induction and nitric oxide production, validating the importance of this hormone in sperm fertilizing ability (Lampiao \& du Plessis 2008).

Finally, $\mathrm{KO}$ studies focused on insulin superfamily members (Baker et al. 1996, Burnicka-Turek et al. 2012), their receptors (Nef et al. 2003) or on intermediaries of insulin signaling pathway (Griffeth et al. 2013), provided further data supporting the importance of insulin signaling pathway on the male reproductive function, namely on testicular aspects and sperm characteristics (Baker et al. 1996, Burnicka-Turek et al. 2012, Griffeth et al. 2013) as well as on male sex determination during development (Nef et al. 2003) are present. 


\section{Data from studies in diabetic individuals/conditions}

There are several details that remain to be clarified when it comes to the mechanisms responsible for the alterations in diabetics' reproductive function. Though hyperglycemia and associated oxidative stress are likely candidates to explain some of the alterations (Agbaje et al. 2007, Shrilatha \& Muralidhara 2007a,b, La Vignera et al. 2009b, Rama Raju et al. 2012), the deregulation in insulin signaling pathway during diabetes cannot be excluded from this network of damage. In fact, having in mind the findings discussed so far, it seems reasonable to hypothesize two ways by which insulin might impact the male reproductive function: through the regulation of glucose metabolism, avoiding the negative impact of hyperglycemia, or inducing alterations due to hypoglycemia or by having a direct role at the cellular level, activating important signaling pathways.

Studies in diabetic individuals or in diabetic conditions, provided important insights concerning the importance of insulin (its absence or excess) to the male reproductive system, with several studies reporting that the reproductive changes found in diabetic individuals could be reverted or attenuated by insulin treatment (Seethalakshmi et al. 1987, Gondos \& Bevier 1995, Ikeda et al. 2000, Yamanaka et al. 2003, Kim \& Moley 2008, Singh et al. 2009, Yonezawa et al. 2009, Schoeller et al. 2012a).

Due to the extensive data available, we will focus on 3 main levels: pre-testicular, testicular and post-testicular.

\section{Pre-testicular level:}

There is a wide disparity regarding the effects of insulin treatment on gonadotrophin levels in diabetic individuals with reports ranging from a total recovery of both $\mathrm{LH}$ and $\mathrm{FSH}$ (Seethalakshmi et al. 1987), to the recovery of just one (Perez Diaz et al. 1982, Hutson et al. 1983, Benitez \& Perez Diaz 1985, Sudha et al. 2000) or even the absence of effects (Steger \& Kienast 1990), suggesting that testicular function regulation is the result of a complex process in which several players are involved.

Other studies have explored these aspects in more detail, and insulin treatment was observed to totally reverse all parameters of pulsatile $\mathrm{LH}$ secretion, which were reduced in diabetic rats and, at least partially, due to a decreased responsiveness of the pituitary to GnRH (Dong et al. 1991).

In a different report, Bucholtz and collaborators have found that LH secretion was reduced in developing diabetic sheep with hypoinsulinemia and that this effect was potentiated by sex steroids (Bucholtz et al. 2000). Yet, insulin treatment was observed to restore LH pulse frequency (Bucholtz et al. 2000). In a follow-up study, the authors observed that central insulin infusion in diabetic sheep increased the cerebrospinal fluid concentration of this hormone, maintaining it at levels similar to those observed after peripheral insulin administration and not altering peripheral insulin or glucose levels. Furthermore, central insulin infusion was observed to increase LH pulse frequency, although in a lower extension than the peripheral one, suggesting that central insulin has also a role in pulsatile GnRH secretion regulation (Tanaka et al. 2000).

Aiming to clarify if the insulin action is dependent on the sexual maturation phase in which diabetes is detected, a study was conducted in both prepubertal and pubertal diabetic rats (Sudha et al. 2000). Insulin was observed to restore serum $\mathrm{LH}$ and testosterone levels in both groups, highlighting the regulatory role of insulin in gonadotrophin secretion and on Leydig cell steroidogenic ability acquisition during sexual maturation. Nonetheless, FSH and prolactin levels were not restored by insulin on prepubertal rats, suggesting that the initiation of diabetes before puberty impairs the functional maturation of the pituitary-testicular axis in a different fashion and that insulin regulates the pituitary differently, depending on the stage of development (Sudha et al. 2000).

\section{Testicular level:}

There are several studies that provide evidence for the direct effect of hyperglycemia and/or insulin deficiency on Leydig cells. In early experiments, it was shown that untreated diabetes caused a reduction in serum $\mathrm{LH}$, testosterone levels and steroidogenic activity and that these parameters were restored by insulin treatment (Tesone et al. 1976, Murray et al. 1981, Perez Diaz et al. 1982, Benitez \& Perez Diaz 1985), raising the question on whether the effects of insulin are directly in the testis or induced through alterations in $\mathrm{LH}$ secretion. Furthermore, it was observed that Leydig cells' LH receptors were decreased in diabetic rats, though the binding capacity was restored after insulin administration (Charreau et al. 1978). The authors suggested that this alteration might be behind the altered responsiveness of diabetic Leydig cells to LH (Charreau et al. 1978). In addition, Paz and Homonnai reported a reduced number of Leydig cells and testosterone secretion in testis of diabetic animals (Paz \& Homonnai 1979). However, in this case, insulin treatment presented no beneficial effects in terms of Leydig cell function (Paz \& Homonnai 1979).

In another study, insulin has also been shown to restore the ultrastructure of diabetic rats' Leydig cells, including the accumulation of lipid droplets, reduction of smooth endoplasmic reticulum and presence of intracellular bodies (Orth et al. 1979). Therefore, the authors suggested that the reduced steroidogenesis commonly observed in diabetic rats might be, at least in part, due to alterations in Leydig cell ultrastructure and function induced by insulin deficiency.

Tremblay's team, after showing that pituitary $\mathrm{LH}$ regulates testicular insulin receptors, measured insulin-binding parameters in testicular membranes of diabetic rats to clarify if the observed alterations in Leydig cell function were due to effects mediated by $\mathrm{LH}$ or to a direct effect of altered $\mathrm{LH}$ levels (Tremblay et al. 1985). The authors observed a decrease in insulin binding in Leydig cell from diabetic rats. As both $\mathrm{LH}$ and insulin receptor are dependent on pituitary LH, whose release is also impaired in diabetes, the authors suggested that $\mathrm{LH}$ is a key factor to explain the detrimental effects on Leydig cells, including decreased androgen levels and alterations in the reproductive organs (Tremblay et al. 1985) and that both $\mathrm{LH}$ and insulin receptors, under the influence of $\mathrm{LH}$ are needed to the correct the function of Leydig cells. 
In a similar study, Ballester and coworkers have shown that insulin and IGF-1 receptors content in the testis of diabetic rats were decreased, mainly in the interstitial tissue (Ballester et al. 2004). Additionally, they observed reduced LH levels and almost no insulin in the serum, which have led them to suggest that this might have contributed to a loss of stimulation of androgen synthesis and cell proliferation, in accordance with the observed decrease in Leydig cell number and function. Therefore, the authors proposed that the alterations in Leydig cells can be a consequence of either an effect of hypoinsulinemia on LH levels or the joint effects of decreased LH and insulin levels on Leydig cells (Ballester et al. 2004). In a different study, following the observation of altered arachidonic acid (AA) biosynthesis and fatty acid composition in Sertoli and Leydig cells of diabetic rats, it was observed that insulin recovered AA biosynthesis, suggesting the participation of insulin also in the regulation of lipid metabolism. Based on the stimulatory effect of AA on testosterone secretion, the authors suggested that this might constitute another route by which insulin deficiency can impact male reproductive function (Hurtado de Catalfo \& De Gomez Dumm 1998).

Furthermore, insulin resistance in men was observed to be associated with decreased testosterone production in response to hCG, further supporting a deregulation in Leydig cell function (Pitteloud et al. 2005a). In a follow-up study, the authors reported that the low testosterone levels observed were not only associated with insulin sensitivity but also with markers of mitochondrial function (Pitteloud et al. 2005b). Nonetheless, a recent study observed no relation between insulin resistance and male reproductive function (Verit et al. 2014). These contradictory results might be related to the different patients' selection criteria and number.

Besides the already mentioned effect of insulin on AA synthesis recovery, few are the studies regarding the effects of insulin replacement on Sertoli cell function of diabetics or in diabetic conditions. In 1983, Hutson described that ABP and FSH levels were altered in diabetic rats but can be recovered with insulin treatment, indirectly indicating a deregulation of Sertoli cell stimulation and function (Hutson et al. 1983).

More recently, testicular insulin levels were observed to be decreased in diabetic rats (Gomez et al. 2009), evidencing that testicular insulin deregulation might be behind the described metabolic and spermatogenic alterations in diabetic individuals. Aiming to clarify whether the reproductive problems associated with diabetes were due to a deficiency in systemic or testicular insulin (or both), Schoeller and coworkers performed an elegant study using as a model the Akita mouse, that presented altered fertility (Schoeller et al. 2012a). This mouse has a mutation in Ins2 gene that results in a nonfunctional insulin expression in the pancreas and testis. Exogenous insulin treatment was observed to rescue the fertility impairment of these mice. The authors proposed that, due to the impermeability of the blood-testisbarrier to insulin, the observed defects in Akita mice fertility are mainly due to systemic alterations, highlighting the importance of pancreatic insulin in the regulation of the HPG. Furthermore, the authors described that Sertoli cells can produce insulin, suggesting a role of these cells in the regulation of testicular insulin signaling (Schoeller et al. 2012a). Nonetheless, this study did not disclose the exact role of testicular insulin and further studies are needed to clarify this point.

\section{Post testicular level}

Epididymis and sperm The epididymis is an essential organ of the male reproductive system, assuring sperm maturation. Therefore, any potential alterations in this organ, such as those occurring during diabetes (Soudamani et al. 2005, Singh et al. 2009) will most likely influence sperm function.

Insulin replacement was observed to have beneficial effects on some features of diabetic epididymis, partially recovering absolute weight, atrophic changes in the epithelium and the lumen diameter, thereby highlighting the importance of insulin in the maintenance of epididymal structure and function (Soudamani et al. 2005). Some years later, insulin was reported to also prevent, either partially or completely, the reduction in testosterone and $\mathrm{ABP}$ levels, secretory activity (carnitine, salicylic acid and glycerylphosphroryl coline) and concentrating capacity observed in the epididymis of diabetic rats, ultimately suggesting the involvement of insulin in sperm maturation too (Singh et al. 2009).

Regarding direct insulin effects on diabetic sperm, restoration of sperm motility and prevention of sperm count decrease was observed in several studies (Singh et al. 2009, Schoeller et al. 2012a).

\section{Ejaculatory and erectile function}

As pointed out, alterations at post-testicular level are also more common in diabetic individuals, as is the case of erectile dysfunction. Although some studies have reported beneficial effects of insulin treatment on some aspects of sexual function such as copulatory behavior and ejaculation (Steger \& Kienast 1990, Yonezawa et al. 2009), few are the reports regarding the effects of insulin on erectile dysfunction (ED). Yet, this process also seems to be prone to the action of insulin. In fact, Yamanaka and coworkers reported that insulin treatment recovered the decrease in mean intracavernous pressure observed in diabetic rats and decreased the apoptotic index in penile crura (Yamanaka et al. 2003). The authors suggested that the insulin-promoted amelioration of the ED in diabetic rats might be mediated by the observed induced decrease in apoptotic index in the penile crura (Yamanaka et al. 2003) and similar results were reported by other authors (Wang et al. 2014, Choi et al. 2015). Furthermore, the observation that men with ED have a high incidence of insulin resistance and that this was positively correlated with increasing severity of ED, provides further evidence for a role of insulin in this process (Bansal et al. 2005).

In a subsequent study, insulin therapy, when given at an early stage of the disease, was found to completely prevent the alterations observed in the ejaculatory function of diabetic rats, such as spontaneous seminal emission, amount of seminal vesicle fluid or amount of ejaculated seminal material. The authors suggested that insulin is likely to have a role on the processes behind seminal emission and/or excretion in rats (Yonezawa et al. 2009).

Overall, acting at all the levels of the male reproductive system and reverting/attenuating the reproductive alterations 
found on diabetic individuals, insulin has an unquestionable role on male fertility. In fact, insulin's positive effects have been reported at the hormonal level, in the testicular cells function (germ and somatic cells), in testicular metabolism, sperm function and also on ejaculatory capacity of diabetic individuals (Table 1). However, it is still to be determined how the oscillations in insulin levels or even the hypoglycemic episodes, which commonly occur during therapy, will impact the male reproductive function.

\section{Biguanides}

Biguanides are a well-established family of compounds used in the treatment of type 2 diabetes from which, the most used and studied one is metformin.

Metformin has been clinically prescribed for about 50 years, being the first-line drug of choice for the management of type 2 diabetes. This drug reduces hepatic glucose production, stimulates glucose uptake and increase insulin sensitivity in peripheral tissues, without causing hypoglycemia (Bailey \& Turner 1996, Pirwany et al. 1999, Lochhead et al. 2000, Zhou et al. 2001, El-Atat et al. 2004). Metformin's mechanism of action, nevertheless, only recently began to be understood. It has been suggested that metformin action is achieved mainly through the inhibition of mitochondrial electron transport chain complex I, which leads to an increase of AMP:ATP ratio, that will then trigger AMPK, switching off the anabolic process. However, an action independent of AMPK has also been suggested with the direct metformin regulation of the gluconeogenic flux or mammalian target of rapamycin (mTOR) complex 1 inhibition. In essence, metformin can attenuate the two main pathways essential for mTOR complex 1 activation by (1) decreasing RHEBmediated signals such as growth factors (IGF-1, insulin), cellular energy status (AMPK), ROS status and ER stress (ATM, REDD1) and (2) decrease amino acid-mediated PAT1/regulator-RAG signaling (Melnik \& Schmitz 2014).

Although the main target of metformin is the liver, it can also act on other tissues/organs, including the reproductive ones. However, the effects of this drug on male reproductive function and fertility remain largely unexplored.

In fact, metformin treatment in diabetic rats has shown to increase body weight (Song et al. 2015), decrease fasting blood glucose (Adaramoye \& Lawal 2014, Song et al. 2015) and significantly decrease diabetesinduced biochemical alterations mediated by oxidative stress, including sperm lipid peroxidation and altered antioxidant levels (Attia et al. 2009). Furthermore, this drug has been reported to restore sperm quality by promoting an increase in sperm count, motility and normal morphology, and overall, reducing sperm genomic instability caused by DNA fragmentation in diabetic rats (Attia et al. 2009). Moreover, when compared to pioglitazone (thiazolidinediones) and sitagliptin (DPP-4 inhibitors/gliptins), metformin has shown to induce the smallest histological modifications on the structure of the testis, epididymis and seminal vesicles as well as restore their weights and promote an increase in testosterone levels (Ayuob et al. 2015). In both these latter findings, the values obtained were similar to the ones found in normal, non-diabetic rats (Ayuob et al. 2015).

Indeed, others have also reported an increase in serum testosterone levels with metformin treatment (Song et al. 2015) and an amelioration of the diabetesinduced testicular pathological changes (Kianifard et al. 2011, Song et al. 2015). Furthermore, while an increase in serum IGF-1 levels and testicular IGF-1 protein and mRNA expression were detected in metformin-treated rats when compared to the untreated diabetic ones, a decrease in growth hormone $(\mathrm{GH})$ levels and testicular $\mathrm{GH}$ protein and mRNA expression were reported (Song et al. 2015). As the GH/IGF-1 axis has been reported to interact with the HPG axis and therefore regulate reproductive function, the observed alterations might explain the improvement of reproductive function following metformin treatment.

However, others have failed to detect any reproductive amelioration with this therapeutic approach. While no effects on absolute and relative testis weights (Adaramoye et al. 2012, Adaramoye \& Lawal 2014) as well as on sperm live/dead ratio (Adaramoye et al. 2012) were reported in metformin-treated rats when compared to the untreated counterpart, a marked decrease in epididymal sperm count, motility and increased testicular lipid peroxidation was observed in this experimental group. Furthermore, these metformintreated rats also presented altered testicular superoxide dismutase, catalase and glutathione activities and severe histological features including seminiferous tubules degeneration, spermatocytes defoliation and necrosis (Adaramoye et al. 2012). Nevertheless, it should be noted that the authors administered metformin to healthy adult rats with apparent normal glucose levels (Adaramoye et al. 2012), which though important to acknowledge metformin's toxicity, it is not quite relevant in a diabetes scenario. Later on, the same group was detected with an increase in sperm motility with metformin treatment to values even similar to the non-diabetic controls; however, no improvement was detected in sperm count or in total sperm abnormalities or sperm live/dead ratio even when compared to the untreated diabetic control group (Adaramoye \& Lawal 2014). Indeed, metformin's action was so poor that also protein and sialic acid contents, glutathione-S-transferase and glutathione levels as well as antioxidant enzymes activities and lipid peroxidation were found unaltered in the testes of these treated animals when compared to the untreated diabetic group and were all altered in relation to the non-diabetic controls. The levels of testosterone, $\mathrm{LH}$, $\mathrm{FSH}$ and prolactin were also reported to be similar to the 
untreated diabetic males and decreased in comparison to the non-diabetic animals, prolactin being the only exception with no changes detected in the latter case (Adaramoye \& Lawal 2014). However, the authors used alloxan to induce diabetes and the outcomes observed suggest metformin's limitation in the management of type 1 diabetes.

Besides type 1 and type 2 diabetes, gestational diabetes can also affect both the mother and the youngster and many reports have pointed toward a positive effect of metformin treatment during pregnancy. Yet, metformin has been shown to cross the placenta (Vanky et al. 2005, Kovo et al. 2008) possibly directly affecting embryonic and fetal development at concentrations approaching the ones found in maternal venous blood (Charles et al. 2006). In fact, studies of metformin exposure in utero have shown some testicular alterations such as diminished Sertoli cell number and reduced seminiferous tubules size in the male mice progeny (Bertoldo et al. 2014). Despite these, the effects of metformin administration during the development and function of the fetal testis has remained largely unexplored.

Using both human and murine organotypic testes cultures in vitro, Tartarin and coworkers have observed an increase in intratesticular lactate secretion upon exposure to $500 \mu \mathrm{M}$ metformin and higher, and reduction in both testosterone production and mRNA expression of factors involved in steroid production (Tartarin et al. 2012). Interestingly, cultured human fetal testes were found to be more vulnerable to metformin than their mouse counterparts as a concentration of $50 \mu \mathrm{M}$, usually measured in patients' blood during therapeutic treatment, was enough to diminish testosterone secretion, while in mouse $500 \mu \mathrm{M}$ was required to promote the same effect (Tartarin et al. 2012). Such difference in sensitivity suggests caution when extrapolating the results, highlighting the need of rigorous comparisons among species. Furthermore, in vivo administration of metformin to pregnant mice at $300 \mathrm{mg} / \mathrm{kg} /$ day, a concentration similar to the one found to obtain a therapeutic effect in diabetic rodents $(50 \mu \mathrm{M})$, was shown to decrease testicular volume without increasing cell death in both fetal and neonatal periods and, in sharp contrast with what was detected in vitro, metformin failed to affect intratesticular lactate secretion. Testicular testosterone was found to be reduced but merely on male fetuses, which are in accordance with the reduced number of Leydig cells per testis only detected in the same period. Conversely, Sertoli cell number was found to be decreased in both fetuses and newborns (Tartarin et al. 2012). Overall, the combined in vitro and in vivo approaches to better evaluate the consequences of exposure to metformin highlight the potential harmful effect of such antidiabetic agent on testicular development. It should be noted, however, that some discrepancies, namely in lactate and testosterone secretion among in vivo and in vitro approaches were observed, suggesting that one should be careful when analyzing the in vitro results and inferring to an in vivo situation or vice-versa. Although these results indicate that during pregnancy metformin should be used with caution, as it may result in gonadal developmental abnormalities, and further studies will be needed to clarify what will be the role of metformin in the offspring of (diabetic) mothers treated with this drug.

Sertoli cells, which are crucial for spermatogenesis, exert a tight metabolic control over such highly dynamic process. Recently, it has been reported that $50 \mu \mathrm{M}$ metformin induces a decrease in mRNA and protein levels of phosphofructokinase 1 (PFK 1), monocarboxylate transporter 4 (MCT4) and glucose transporters GLUT1 and GLUT3 in rat Sertoli cells cultured in high glucose conditions, but it has no effects on lactate dehydrogenase (LDH) mRNA or protein levels. However, an improved glycolytic flux was suggested as $\mathrm{LDH}$ activity and both alanine and lactate production were increased in metformin-treated Sertoli cells (Alves et al. 2014). Considering that glucose taken up by Sertoli cells is then converted into lactate via LDH and that such metabolite is necessary for energy production in the developing germ cells, regulating spermatocyte survival and metabolic activity, metformin has been suggested as a worthy drug for the management of male individuals diagnosed with type 2 diabetes (Alves et al. 2014). In support of such evidence is the inhibition of germ cell apoptosis by lactate in the human testis (Erkkila et al. 2002), leading the authors to propose that the treatment with a pharmacological dose of metformin may increase the male reproductive potential of diabetic patients via inhibition of germ cell apoptosis (Alves et al. 2014).

As previously mentioned, diabetic men commonly experience ED. However, the effects of metformin administration in this diabetes-mediated dysfunction have been deeply overlooked. Indeed, the majority of the existing literature has only addressed the effects of metformin on a non-diabetic ED context, and even so, the number of reports available is very limited. One of these is a prospective, randomized, controlled and double-blind placebo study where metformin was shown to improve erectile function and reduce insulin resistance in non-diabetic patients with ED and poor response to the phosphodiesterase-5 inhibitor sildenafil (Rey-Valzacchi et al. 2012). However, though considered mild and not significant enough to discontinue the treatment, patients treated with this drug presented more adverse effects than those receiving the placebo, mainly gastrointestinal effects (Rey-Valzacchi et al. 2012). Furthermore, Kim and coworkers have also reported that metformin is capable of restoring nitric oxide synthase protein expression in the penile tissue of rats fed with a high-fat diet (Kim et al. 2006) but whether such treatment could be beneficial to reestablish erectile function in an ED model was not known until 2013. At that time, using angiotensin II to promote hypertension 
(which is considered a major risk factor for ED), Labazi and coworkers have shown that in angiotensin-treated rats, metformin increased eNOS phosphorylation and improved erectile function by re-establishing normal cavernosa smooth muscle tone (Labazi et al. 2013).

In summary, although limited, the available literature suggests that metformin might exert positive effects on the male reproductive function of diabetic individuals as other have also highlighted (Ferreira et al. 2015). Yet, its efficiency does not reach the observations made in non-diabetic controls (Kianifard et al. 2011, Ayuob et al. 2015, Song et al. 2015) (Table 1). Furthermore, when used in non-diabetic or in other than type 2 diabetes conditions, metformin might cause undesirable effects at the reproductive level, stressing the need of further studies to disclose metformin's pros and cons at this level. This should be performed mainly in humans, as a species-specific sensitivity seems to occur.

\section{Sulphonylureas and meglitinides}

Sulfonylureas (SUs) are a widely prescribed class of oral antidiabetic drugs for the treatment of type 2 diabetes mellitus (Ashcroft 1996). These compounds, introduced in 1942, stimulate insulin secretion from $\beta$-pancreatic cells, thus having a hypoglycemic ability (Janbon et al. 1942).

The first generation of sulfonylureas started with the introduction of tolbutamide followed by chlorpropamide, acetohexamide and tolazamide (Seltzer 1980). Later, a second generation was developed, which at that time included the compounds gliclazide, glyburide (glibenclamide), glimepiride and glipizide (Tommasini 1975, Kar \& Holt 2008, Basit et al. 2012). Despite all acting similarly, they differ in the intrinsic antidiabetic activity, onset, period of action and elimination, and affinity for SU receptor (Jackson \& Bressler 1981, Lebovitz 2001).

Although SUs have been the mainstay of pharmacotherapy for treating type 2 diabetes mellitus, some concern has been raised regarding their safety, as they contribute to increased risk of hypoglycemia and weight gain (Thule \& Umpierrez 2014).

Through the inhibition of the ATP-dependent potassium channels $\left(K_{\text {ATP }}\right)$, SUS stimulate insulin secretion in $\beta$-pancreatic cells, independently of blood glucose levels, and are referred as insulin secretagogues (Sturgess et al. 1985, Trube et al. 1986). Under normal conditions, these channels are open, allowing the efflux of potassium and polarization of the cell membrane (Burke et al. 2008). When sulfonylureas bind to these receptors the $\mathrm{K}^{+}$efflux is disrupted, which in turn leads to $\mathrm{Ca}^{2+}$ influx, resulting in cell depolarization and ultimately release of insulin-containing granules (Panten et al. 1996).

Besides $\beta$-pancreatic cells, these $K_{\text {ATP }}$ channels have been observed in many other cells (Ashcroft \& Gribble 1998), including mouse spermatogenic cells and mature sperm, through the detection of mRNA levels and whole-cell patch-clamp/functional studies (Munoz-Garay et al. 2001, Acevedo et al. 2006). In these studies, the authors could provide evidence for the contribution of these channels to the hyperpolarization event occurring during sperm capacitation, and further hypothesized that they might also have a role in other important processes like spermatogenesis, sperm hyperactivation and acrosome reaction (Munoz-Garay et al. 2001, Acevedo et al. 2006).

Moreover, additional results were obtained with the identification of these $K_{\text {ATP }}$ channels in epididymal epithelial cells from different mammalian species. Although the role of these channels in the epididymis is not clear, the authors suggested that they might be involved in several processes occurring along the epididymal epithelium, such as protein secretion and fluid-electrolyte transport, crucial for sperm maturation (Lybaert et al. 2008).

Since the presence of $\mathrm{K}_{\text {ATP }}$ channels on spermatogenic cells has been established, and knowing their role on sperm capacitation and its related events, it is important to analyze possible outcomes of sulfonylureas administration to (diabetic) male individuals.

Despite the persistent use of tolbutamide since its initial administration in 1956 (Scott \& Poffenbarger 1979), few are the studies that report an effect on sperm and general spermatogenic activity. One of these studies is the already mentioned work by Acevedo and coworkers (Acevedo et al. 2006) that reported blocked hyperpolarization and a dose-dependent decrease in the percentage of acrosome-reacted mouse spermatozoa after exposure to this sulfonylurea in capacitating media. In contrast, no effects on sperm undergoing acrosome reaction were observed when the drug was tested after capacitation. These results indicate that tolbutamide prevents capacitation (Acevedo et al. 2006), highlighting the potential of this compound to interfere with the fertilizing capacity of male gametes. Nonetheless, the role of this drug in a diabetic context is still to be determined.

One of the first reports regarding the 'second generation' of SUs was on the sulfonylureas glibenclamide and gliclazide. This study has shown their spermicidal potential in vitro by describing a total loss of human sperm viability and motility, possibly due to an elevation of intrasperm calcium concentration $\left(\left[\mathrm{Ca}^{2+}\right]\right.$ is), that the authors proved to be resulting from the inhibition of the $K_{\text {ATP }}$ channels (Kumar et al. 2008). In a different study, it was proved that glibenclamide exerted protective effects on diabetic rats' fertility (Rabbani et al. 2010b). Upon induction of a diabetic state through administration of nicotinamidestreptozotocin, the overall fertility parameters were affected showing an increase in shape abnormality and a reduction in sperm count as well as testis weight. However, after treatment with glibenclamide, there 
was a decrease in shape abnormality, although no changes in sperm count were observed (Rabbani et al. 2010b). Similarly, the SU glimepiride was observed to have the same protective effect (Rabbani et al. 2009). The diabetic rats showed increased sperm morphology abnormalities and decreased sperm count and testis weight. Again, after treatment with the sulfonylurea, sperm morphological abnormalities decreased and, in this case, the authors observed an increase in sperm count also (Rabbani et al. 2009). Both studies suggested a protective role of glibenclamide and glimepiride at sperm level in diabetic conditions. Furthermore, as the authors observed a decrease in oxidative stressrelated parameters after glibenclamide and glimepiride treatment, they suggest that the antioxidant properties of these drugs might reduce the oxidative stressassociated complications, including fertility problems (Rabbani et al. 2009, 2010b). However, different results were reported by Adaramoye and coworkers that, after glibenclamide treatment in healthy rats, observed a reduction in sperm motility and count while in the testis, lipid peroxidation was increased and the activities of antioxidant enzymes were decreased (Adaramoye et al. 2012).

Finally, gliclazide was also found to promote a significant increase in testicular $3 \beta$-hydroxysteroid dehydrogenase (HSD) and 17 $\beta$-HSD enzymes' activity levels and serum testosterone levels in diabetic rats when compared to the untreated ones (Nelli et al. 2013), suggesting a positive effect of these SUs on the steroidogenesis of diabetic males.

No justification or suggestion has been made regarding the discrepant outcomes of SUs on male fertility. However, when analyzing the reported results, we can ascertain that when used in vitro, SUs have detrimental effects on capacitation and viability, both in human and mouse sperm cells (Acevedo et al. 2006, Kumar et al. 2008). On the other hand, when studies were performed in diabetic rats, the administration of SUs showed a positive effect at sperm and testicular level, reversing the adverse effects promoted by the disease (Rabbani et al. 2009, 2010b, Nelli et al. 2013) (Table 1). Nonetheless, a completely different scenario occurs when studies were performed in non-diabetic rats (Adaramoye et al. 2012).

Although when analyzing these studies there are several factors to consider, such as the type and dosages of SUs, the different species used or the specific parameters evaluated, it is reasonable to conjecture that while the beneficial effects of SUs in vivo might be a result of the overall action throughout spermatogenesis, resulting in sperm with higher quality, when in vitro, with the mature sperm cell as a final target, the panorama might be different. Furthermore, we should not disregard that while the antidiabetic properties of SUs might be effective in diabetic individuals and potentially translated in a better sperm quality, this might not be the case in non-diabetic conditions, in which the drug might inclusively cause detrimental effects.

Furthermore, sulfonylureas therapy may have another downside. In fact, an increased risk of ED has been associated with these antidiabetic agents. Although the mechanisms behind this association are not fully unveiled, it has been suggested that the inhibition of $\mathrm{K}_{\text {ATP }}$ channels promoted by SUs might impair the vasodilation needed for the erection (Sehra et al. 2011). However, more studies are needed to fully disclose this issue.

Overall, although some controversy exists regarding the effects of SUs on the male reproductive function, these drugs are still often prescribed to type 2 diabetic patients, stressing the need of further studies to clarify the safety of this method in terms of male reproductive health.

In 1995, a new family of oral antidiabetic agents was introduced: the meglitinides analogues, also known as non-sulfonylurea insulintropic agents. This family is composed by repaglinide, nateglinide and mitiglinide (Malaisse 2003). Like sulfonylureas, meglitinides promote insulin secretion through $\mathrm{K}_{\text {ATP }}$ channels inhibition, increasing intracellular calcium concentration (Malaisse 1995, Landgraf 2000), and bind to the same receptor, the sulfonylurea receptor (SUR) (Dabrowski et al. 2001). However, these analogues are proposed to be superior to $\mathrm{SUs}$, as they are not frequently linked to hypoglycemia occurrence (Malaisse 1995, Landgraf 2000).

Nonetheless, these compounds also seem to affect the sperm. In one of the few studies performed, besides sulfonylureas, the authors also used repaglinide. Similar to SUs, repaglinide produced a time- and dosedependent decrease in human sperm viability resulting, ultimately, in the complete loss of viable male gametes. This outcome would also propose repaglinide as a spermicidal agent (Kumar et al. 2008). Nonetheless, the scarce information in terms of safety highlights the need of further studies.

\section{Thiazolinediones/glitazones}

Thiazolidinediones (TZDs) or glitazones are another class of medication often used in the treatment of type 2 diabetes. These insulin sensitizer agents improve glycemic control, without causing hypoglycemia (ADA $2016 d$ ) and consist of pioglitazone, rosiglitazone and troglitazone.

Although troglitazone was the first to be approved for use back in 1997, it was quickly removed from the market due to the reported high frequency of liver injury (Gitlin et al. 1998, Neuschwander-Tetri et al. 1998, Herrine \& Choudhary 1999, ADA 2016d).

Pioglitazone and rosiglitazone were approved in 1999, and they can be either used as a monotherapy or in combination with metformin, sulfonylureas or insulin. Contrarily to troglitazone, these have been rarely linked to acute liver injury. However, the increased risk of cardiac-associated events led the 
European Medicines Agency to remove rosiglitazone from the European market. Nevertheless, it remains available in the US, although its use has been restricted. On the other hand, although reports suggested that the extended use of pioglitazone may significantly elevate the risk of bladder cancer, the evidence was considered insufficient to warrant its removal from the market by the health regulation organisms and in general, pioglitazone presents a more favorable safety profile, therefore being the most extensively used TZD (El-Kaissi \& Sherbeeni 2011, ADA 2016d).

The antidiabetic effect of TZDs is accomplished by the activation of peroxisome proliferator-activated receptor in their gamma isoform (PPAR $\gamma$ ) (Lehmann et al. 1995). PPARs are a group of nuclear receptor proteins that function as transcription factors regulating the expression of genes (Berger \& Moller 2002) and therefore participate in a wide range of processes, such as lipid homeostasis (Evans et al. 2004), angiogenesis, prostaglandin production (Desvergne \& Wahli 1999), steroidogenesis (Gasic et al. 1998), inflammation, apoptosis, cellular proliferation and oxidative stress responses (Staels \& Fruchart 2005).

As PPAR $\gamma$ synthetic agonists, TZDs influence the transcription of several genes that participate in glucose and lipid metabolism and general energy homeostasis (Hauner 2002). In this way, TZDs reduce insulin resistance not only in adipose tissue, where the PPAR $\gamma$ is mainly expressed, but also in the liver and muscle, probably through endocrine signals from the adipocytes (Hauner 2002).

Notably, the presence of PPAR $\gamma$ was described in human sperm (Aquila et al. 2006) and testicular cells, including somatic (Braissant et al. 1996, Bhattacharya et al. 2005, Mansour et al. 2009, Thomas et al. 2011), and germ cells (lbabe et al. 2005, Thomas et al. 2011) suggesting a potential role of TZDs on male fertility. Since diabetes is rising and leads to several health complications, including reproductive problems, it is therefore important to clarify the safety of these antidiabetic drugs at this level. Yet, in this review, we will not discuss troglitazone once it was on the market for a short period.

Rosiglitazone treatment, at a therapeutic dose, showed beneficial effects at the testicular level by reversing the detachment and disorganization of germ cells, a feature found in the seminiferous tubules of diabetic animals (Mansour et al. 2009). The authors suggested that these effects were probably due to an amelioration of the oxidative stress level, thought to be behind the testicular alterations observed in diabetic rats (Mansour et al. 2009).

Furthermore, although an inhibitory steroidogenic action by TZDs has been reported (Furnsinn et al. 2002, Vierhapper et al. 2003, Kempna et al. 2007), studies regarding TZDs effects in diabetic individuals' testosterone levels are scarce.
In non-diabetic men, rosiglitazone was observed to decrease serum testosterone and their production ratio (Vierhapper et al. 2003), while in rodents, no changes were reported in plasma testosterone levels (Couto et al. 2010), neither in the fetuses' testes after gestational exposure (Boberg et al. 2008). On the other hand, studies with diabetic animal models, reported a decrease in serum testosterone levels in diabetic fatty rats, as expected, and the treatment of these animals with rosiglitazone kept testosterone levels low, showing that rosiglitazone neither restored nor reduced serum testosterone levels (Mansour et al. 2009). Moreover, rosiglitazone treatment also did not alter the concentrations of the gonadotropins $\mathrm{LH}$ and $\mathrm{FSH}$ and serum estradiol, demonstrating no impact on the sex hormones of diabetic rats (Mansour et al. 2009).

There are also some studies that focused on the impact of rosiglitazone on testicular cells, however, not in diabetic conditions. To verify the ability of rosiglitazone to directly affect testosterone production by Leydig cells, Couto and coworkers performed an ex vivo assay using isolated Leydig cells from the testes of rosiglitazone-treated rats. Although the testosterone levels were not altered in the plasma of these animals, rosiglitazone modified the steroidogenic response of these cells resulting in a decrease in basal and induced testosterone production (Couto et al. 2010). Furthermore, ultrastructural analysis revealed alterations in the mitochondrial morphology that could have led to a mitochondrial dysfunction in Leydig cells, compromising steroids biosynthesis (important steps of which occur in mitochondria) and suggesting that the lower levels of testosterone produced by these cells could be due to mitochondrial damage induced by rosiglitazone (Couto et al. 2010). Nonetheless, it is still to be determined how rosiglitazone will act in diabetic conditions. In fact, though these studies are important as they provide information about the drug mechanism of action on testicular cells, they are irrelevant in terms of safety for diabetic individuals' reproductive function. Furthermore, the use of TZDs in non-diabetic settings, in which the insulin-sensitizing effects have no logical point, might blur the obtained results, thus avoiding the full understanding of the effects of these drugs on diabetic males' reproductive health.

Although there are no reports about the effect of rosiglitazone in sperm parameters of diabetic individuals, it was demonstrated that incubation of sperm from normozoospermic patients with rosiglitazone increased sperm motility and induced capacitation and acrosome reaction (Aquila et al. 2006). The authors also showed that rosiglitazone interfered with sperm glucose and lipid metabolism and, although not evaluated, this might constitute a way by which this drug can exert positive effects during diabetes due to an insulin sensitization action on sperm. Conversely, in a healthy rat model, rosiglitazone did not produce any effect on sperm 
morphology and count (Rabbani et al. 2008), stressing the need of more evidence, not only to dissect the role of this drug on sperm function but also to get new insights about the possible consequences of rosiglitazone treatment in the sperm quality of diabetic patients.

In summary, although rosiglitazone was highly marketed for several years due to their antidiabetic properties, its effects on male reproductive system are not fully disclosed and more studies are needed to determine its safety having in regard the male reproductive function.

Currently, pioglitazone is the only TZD that remains to be prescribed, at least in Europe, and there are also some reports regarding its effect on male reproductive function. The studies of Gumieniczek and coworkers have focused on the effects of pioglitazone treatment $(1 \mathrm{mg} / \mathrm{kg} /$ day $/ 4$ and 8 weeks) in the testicular tissue of alloxan-induced hyperglycemic rabbits (Gumieniczek et al. 2008, 2011). Based on the assumption that high levels of reactive oxygen/nitrogen species are present in the plasma of diabetic individuals and that this type of overproduction as well as inflammation is also evident at the testicular tissue level (Ceriello et al. 2001, Marfella et al. 2001, Shrilatha \& Muralidhara 2007a), the authors investigated the effects of pioglitazone on these aspects. An amelioration in the activity of several plasma anti-oxidative enzymes, a reduction in testicular lipid and protein oxidation as well as myeloperoxidase levels, an enzyme released by inflammatory cells after infectious and/or inflammatory stimuli, and a normalization of aconitase enzyme activity, a sensitive target of reactive oxygen/nitrogen species and a readout of mitochondrial function, were observed in the testis of these hyperglycemic animals (Gumieniczek et al. 2008, 2011). It is therefore clear that pioglitazone treatment can modulate the oxidative stress associated with the diabetic condition exerting protective effects in hyperglycemic rabbit testis. However, in these studies, pioglitazone failed to affect blood glucose and insulin concentrations, probably because this diabetic rabbit model was not insulin resistant but insulin deficient. For this reason, in this case, the antioxidant effects of pioglitazone cannot be attributed primarily to its antihyperglycemic action, suggesting that this drug reduces free radicals' overproduction directly and indirectly through inhibition of inflammatory mechanisms.

The effects of pioglitazone on the male reproductive function were also studied in other animal models for diabetes as is the case of low-dose STZ-induced type 2 diabetic rats. These diabetic animals presented a reduced weight of reproductive organs (testis, epididymis and seminal vesicle), a disorganized germinal epithelium and an edematous thickened interstitial connective tissue, when compared to the non-diabetic controls. Pioglitazone treatment $(20 \mathrm{mg} /$ $\mathrm{kg} /$ day/6 weeks) increased the testis weight and caused a decrease in the epididymis weight. Furthermore, pioglitazone-treated animals showed several histopathological changes in the testis, epididymis and seminal vesicles, that the authors hypothesized to be consequences of lipid peroxidation that remained high in these animals despite the treatment (Ayuob et al. 2015). Diabetes also negatively affected androgen, estrogen and their receptors (AR and ER respectively), known to have an essential role in male fertility; however, no improvements were observed after pioglitazone treatment that, on the contrary, was observed to cause a reduction in testicular $E R \alpha$ and $E R \beta$ immunoexpression and to suppress $E R \beta$ and AR immunoreactivity in epididymis and seminal vesicles (Ayuob et al. 2015). Based on these results, the authors warn for the use of pioglitazone on young diabetic males, as their reproductive capacity might be compromised. Although not discussed by the authors, it is possible that, the observed effects might also be due to the high dose $(20 \mathrm{mg} / \mathrm{kg} /$ day $/ 6$ weeks) administered to these animals. In fact, it was shown that at a low dose $(1 \mathrm{mg} / \mathrm{kg} /$ day) (Gumieniczek et al. 2008, 2011) even over a longer period (8 weeks) (Gumieniczek et al. 2008), pioglitazone exerts a clear protective effect in the modulation of oxidative stress associated with the hyperglycemic condition. Besides that, beyond the associated differences related to the species utilized, there is also a difference in the disease model since the pioglitazone-negative effects associated to a higher dose tested were reported in STZ-induced type 2 diabetic animals (Ayuob et al. 2015), while the positive effects found were reported in a type 1 hyperglicemic model (Gumieniczek et al. 2008, 2011).

The effects of pioglitazone on testicular cells are another important aspect. As Sertoli cells exert a crucial role in the spermatogenic process, the evaluation of their metabolism can be a good approach to identify possible effects of pioglitazone therapy. In human Sertoli cells cultured in high glucose conditions (that mimic diabetes), pioglitazone, at a pharmacological concentration $(10 \mu \mathrm{M})$, increased the glycolytic efficiency and stimulated the lactate production, which is essential to sustain and preserve spermatogenesis. At this concentration, pioglitazone did not alter the levels of mitochondrial protein complexes neither mitochondrial membrane potential. However, with the sub- and suprapharmacological concentrations, some alterations were reported at the mitochondrial level, which once again strengthens the importance of dosage to obtain better treatment quality (Meneses et al. 2016).

Besides the testis, the effects of pioglitazone were also studied in sperm. In fact, based on the purported antioxidant properties of pioglitazone, Rabbani and coworkers investigated the effects of different concentrations of this drug on sperm morphology and count in healthy rats, after acute and chronic exposure (Rabbani et al. 2008). Although pioglitazone did not produce any variation in sperm count (chronic exposure at the highest dose tested $-100 \mathrm{mg} / \mathrm{kg} / 4$ weeks), 
a decrease in the number of defective sperm was noted, probably due to the antioxidant properties of pioglitazone (Rabbani et al. 2008). Nonetheless, this study had a major flaw in the experimental design that is the lack of a diabetic model. Therefore, in a following study, the authors used nicotinamide-streptozotocininduced type 2 diabetic rats that presented the typical alterations in the antioxidant status and also in sperm parameters (Rabbani et al. 2010a). The authors reported that the higher dose of pioglitazone $(10 \mathrm{mg} / \mathrm{kg} / 4$ weeks $)$ reversed all the effects of the hyperglycemic status, presenting a decrease in blood glucose and lipid peroxidation, an increase in serum antioxidant GSH and GPx enzyme, as well as a decrease on sperm shape abnormalities accompanied by an increase in sperm count. This suggests that the beneficial effects of pioglitazone on sperm morphology of diabetic rats might be mediated by its antioxidant properties (Rabbani et al. 2010a), therefore being in accordance with the previous reports showing that the oxidative stress caused by hyperglycemia might be behind the altered seminal quality of diabetic individuals, compromising their fertility (Amaral \& Ramalho-Santos 2014).

Finally, the diabetes-associated ED, which is mainly a vasculogenic problem caused by arterial insufficiency and corporal veno-occlusive dysfunction (CVOD), has been poorly addressed in an antidiabetic treatment context. Yet, diabetic $(\mathrm{fa} / \mathrm{fa})$ rats with penile corporal fibrosis, oxidative stress and CVOD presented improvements in these aspects by long-term, low-dose $(0.6 \mathrm{mg} / \mathrm{kg})$ pioglitazone treatment with no reduction in glycemia, suggesting a vasculoprotective role of this drug, independent of its antidiabetic action (Kovanecz et al. 2006).

We can conclude that besides the antidiabetic one, pioglitazone present other properties, as antioxidant and anti-inflammatory, that might mediate improvements in male reproductive function (Table 1 ). Yet, this seems to also depend on the drug dose administered or animal model used, which might in fact be the basis of the contradictory reports. Therefore, the use of pioglitazone should be restrained in young diabetic males while more consistent data are not gathered regarding this topic.

\section{GLP1 and DPP4 inhibitors}

Glucagon-like peptide (GLP1) is an incretin, a hormone produced by the small intestine cells following nutrient intake, whose levels are decreased in type 2 diabetic patients. This hormone induces the secretion and release of insulin and, in animal models, it was shown to promote an increase in the $\beta$ cell mass (Hvidberg et al. 1994, Wajchenberg 2007). Furthermore, GLP1 decelerates gastric emptying causing a satiety feeling and diminishes postprandial glucagon production, thus contributing to a decline in blood glucose levels (El-Kaissi \& Sherbeeni 2011). A role in lipid metabolism regulation has also been reported, suggesting that this compound can contribute to weight loss (DallingaThie \& Nieuwdorp 2015). However, the half-life of this substance in vivo is of about two minutes due to its rapid metabolism by the dipeptidyl-peptidase-4 (DPP-4) enzyme (Gupta 2013).

Currently, the GLP-1 analogues available and approved by the Food and Drug Administration (FDA) for type 2 diabetes treatment are exenatide, dulaglutide, albiglutide and liraglutide that differ mainly in dosage and type of administration (Miller et al. 2014). Nonetheless, not much information exists regarding their effects on male reproductive function.

In the first report regarding this subject, researchers tested the effect of exendin-4 (endogenous bioavailable version of exenatide) on the male reproductive function of healthy mice (Ahangarpour et al. 2014). It was observed that the administration of 1 and $10 \mathrm{nmol} / \mathrm{kg}$ of exendin-4 increased epididymal sperm count and testis weight. Furthermore, both treatments led to a decrease in the $\mathrm{LH}$ and FSH levels that, in the lower dosage, was accompanied by an increase in testosterone levels (Ahangarpour et al. 2014), suggesting that exendin-4 interfered in the HPG regulation.

Posteriorly, Zhang and coworkers evaluated the treatment of high-fat-induced obese mice with exenatide on their fertility (Zhang et al. 2015). Exenatide was observed to reverse the negative effects of obesity on sperm function by increasing sperm motility and mitochondrial membrane potential while reducing DNA damage. Also, the treatment did not change the volume of the testis nor affected the testosterone levels. Furthermore, a reduction in the expression of proinflammatory cytokines in the testis, like TNF- $\alpha$, MCP-1 and F4/80, was observed (Zhang et al. 2015).

The different effects of exenatide on testosterone levels and testis weight among studies may be due to the fact that in the first study, the authors used normal rats, with apparently no metabolic defects, while in the later, the authors used an obese diabetic animal model, in which insulin resistance, as well as metabolic deregulation is highly probable (Gomez-Hernandez et al. 2016). Therefore, in this last study, the beneficial effects might have been mediated by an improvement in insulin signaling and overall metabolic status. Moreover, the observed anti-inflammatory effects of this drug might have also played a role, as suggested by the authors.

In humans, there is a single case report in which it was observed that the treatment of a diabetic man with the GLP1 liraglutide led to interrupted sperm production, which was restored after 5 months without taking the substance. The authors proposed that this was due to a reduction of testosterone pulses induced by the infusion of that GLP1 analog (Fontoura et al. 2014).

Overall, from the data we presented here, it is clear that more studies are needed to disclose the exact role of 
GLP-1 on male reproductive function, in particular that of diabetic individuals.

Another explored method to increase incretin hormones endogenous levels is by preventing their rapid degradation through the inhibition of the enzyme dipeptidyl peptidase 4 (DPP4). Sitagliptin, saxagliptin, linagliptin, vildagliptin and alogliptin are the DPP4 inhibitors currently in use, the first being the most studied one as it was the first to be approved for therapeutic purposes (Stein et al. 2013). Unfortunately, their effects on male reproductive function remain largely unexplored.

The first evidence was from a case study of a diabetic man treated with sitagliptin $(50 \mathrm{mg} /$ daily), that showed a progressive decrease in semen volume as well as in sperm concentration and motility (Hibi et al. 2011). Furthermore, the patient presented low levels of free testosterone. For that reason, the treatment was discontinued and the following semen analysis revealed a recovery of semen parameters (Hibi et al. 2011). This case report suggested that DPP-4 inhibitors may have a negative effect on diabetic male's fertility. However, since then, few studies were conducted to clarify this subject.

In a more recent work, the treatment of STZinduced diabetic rats with sitagliptin $(30 \mathrm{mg} / \mathrm{kg} /$ day) slightly decreased the pathological changes caused by diabetes in terms of structure and weight of the testis, epididymis and seminal vesicle (Ayuob et al. 2015). However, the treatment was not able to achieve a complete reversion of the diabetic phenotype. Furthermore, despite the fact that the testis of sitagliptin-treated rats presented the highest number of spermatocytes in different mitotic stages, it was observed that the treatment failed to recover testosterone levels. Additionally, rats under sitagliptin treatment presented decreased expression of estrogen and androgen receptors in the epididymis and in seminal vesicles (Ayuob et al. 2015). For these reasons, the authors suggested that this treatment should be avoided in young male diabetics.

In summary, although the studies on this topic are scarce, the available information points to a rather adverse effect of these antidiabetic agents on male fertility (Table 1), warning for their use in diabetic males, at least during their reproductive age, until more information is available regarding their safety at this level.

\section{Other antidiabetic drugs}

In this subsection, we will discuss reports regarding the effects of other antidiabetic drugs, less used and studied, such as $\alpha$-glucosidase inhibitors, bile acid sequestrants, sodium-glucose co-transporter 2 (SGLT2) inhibitors and amylin analogues.
The $\alpha$-glucosidase inhibitors act by inhibiting the intestinal $\alpha$-glucosidase, that will result in delayed carbohydrate absorption and lowering of blood glucose levels. They do not directly target insulin production but instead promote GLP1 hormone secretion increase (Stein et al. 2013).

The two FDA-approved $\alpha$-glucosidase inhibitors for type 2 diabetes treatment are acarbose and miglitol (Stein et al. 2013) and their effect on male fertility is still to be addressed. In fact, to our knowledge, there was only one study that evaluated the effect of acarbose on the fertility of STZ-induced diabetic rats (Sadeghi et al. 2013). It was observed, that the reduction on the numbers of spermatogonial cells, spermatocytes and Sertoli cells in the testis was lower in the diabetic rats treated with acarbose than that detected on untreated diabetic rats (Sadeghi et al. 2013), suggesting that this drug might have positive effects on reproductive aspects of diabetic individuals. Nonetheless, further research on this topic should be of utmost importance.

Regarding bile acid sequestrants, although they were originally prescribed to treat hyperlipidemia, they were also found to reduce blood glucose levels (Garg \& Grundy 1994). The responsible mechanism for this action is not completely understood, but the activation of farnesoid $X$ receptor or the stimulation of incretin hormones secretion might be involved (Stein et al. 2013). Currently, there is only one bile acid sequestrant approved for diabetes treatment, colesevelam, normally prescribed in combination with other antidiabetic drugs (Stein et al. 2013).

We could find only one study regarding the effects of colesevelam on male fertility. This study, conducted in Sprague-Dawley rats, reported no differences on sperm concentration and motility neither in matting and litter size, between the controls and the treated groups (Marquis et al. 2004). Based on these results, colesevelam does not seem to be detrimental for male reproductive function, but this does not exclude the need of further research to clarify this subject.

Besides all the mentioned antidiabetic drugs, there are also sodium-glucose co-transporter 2 (SGLT2) inhibitors, that lead to a reduction in blood glucose levels by increasing glucose urinary excretion (Cuypers et al. 2013, Ji et al. 2014). Importantly, the increase of glucose levels in the urine augments the incidence of urinary and genital tract infections in males (Cuypers et al. 2013, Ji et al. 2014); however, there are no other reports on the effects of this drug in the male reproductive system. On the other hand, there are also the amylin analogues, whose secretion is impaired in diabetic patients (Young 2005). Amylin is co-secreted with insulin and promotes the reduction of blood glucose levels, suppresses glucagon production and reduces 
satiety (Hoogwerf et al. 2008). However, to the best of our knowledge, no studies exist regarding the effects of these compounds at the male reproductive level.

\section{Concluding remarks}

The impact of diabetes on male reproductive function is concerning mainly due to the alarming increase of the disease worldwide, which is translated into augmented chances of affecting males at the acme of their reproductive window thus contributing to the general decline in fertility rates.

Considering that the cornerstone for the disease management is the glycemic control, achieved through several therapeutic approaches, it is of utmost importance to understand how these treatments affect the male reproductive health, to guarantee that this is maintained during antidiabetic therapy. As this issue is not commonly addressed, we made a comprehensive analysis and a critical review of the available reported data.

While for insulin no doubts exist regarding its importance for male reproductive function, easily attested by the promoted recovery of the reproductive impairment in insulin-dependent diabetic individuals, and for other treatments, this connection is not straightforward. In fact, studies with other antidiabetic drugs originated controversial results that, in our point of view, might be related with marked differences in the study design. Specifically, one of the main constraints that we have found was the use of these drugs in non-diabetic conditions, which we believe might have influenced the obtained results. In fact, if the action of these drugs is directed to improve glycemic control and revert diabetic-associated alterations, and, unlike insulin, they do not normally exist in the body, it is logical to suggest that while studies performed in non-diabetic conditions might be useful to clarify some details regarding their mechanisms of action, the biological relevance in a disease scenario is questionable. In fact, we could detect that, in these conditions, even detrimental effects were reported, contrasting with the positive effects observed in diabetic conditions.

Nonetheless there are still questions to be answered, such as, what will be the influence of the insulin levels variation, that occur during therapy, as well as of the hypoglycemic episodes, a common consequence of several therapies, at the male reproductive level. Therefore, it is crucial to continue research on this topic.

Overall, this stresses the need to engage diabetic patients in informative actions regarding these topics, making them aware not only about the possible impact of diabetes on their reproductive health and fertility potential, as well as of the associated therapies, ultimately mobilizing them to participate in clinical trials. On the other hand, this will expand our knowledge on these topics with the ultimate goal of improving reproductive healthcare.

\section{Declaration of interest}

The authors declare that there is no conflict of interest that could be perceived as prejudicing the impartiality of this review.

\section{Funding}

SA, S R and M S are supported by the Portuguese funding agency for science and technology (FCT-SFRH/BPD/110160/2015; PD/ BD/128237/2016 (PhD Programme in Experimental Biology and Biomedicine) and SFRH/BD/86260/2012, respectively); R S T and A F S are recipients of a fellowship at the scope of the project INNOTECH 2015 CSD006002 (08). C N C is funded by FEDER, through Programa Operacional Factores de Competitividade - COMPETE 2020 and National funds via FCT under the project POCI-01-0145-FEDER-007440.

\section{Acknowledgments}

The authors would like to thank to all the members of the Biology of Reproduction and Stem cell research group (CNC) for all the fruitful discussions. J Saints is acknowledged for proof reading of the final manuscript.

\section{References}

Acevedo JJ, Mendoza-Lujambio I, de la Vega-Beltran JL, Trevino CL, Felix R \& Darszon A 2006 KATP channels in mouse spermatogenic cells and sperm, and their role in capacitation. Developmental Biology 289 395-405. (https://doi.org/10.1016/j.ydbio.2005.11.002)

ADA (American Diabetes Association) 2016a Strategies for improving care. Diabetes Care 39 (Supplement 1) S6-S12.

ADA (American Diabetes Association) 2016 $\mathrm{b}$ Classification and diagnosis of diabetes. Diabetes Care 39 (Supplement 1) S13-S22.

ADA (American Diabetes Association) 2016c Glycemic targets. Diabetes Care 39 (Supplement 1) S39-S46.

ADA (American Diabetes Association) 2016d Approaches to glycemic treatment. Diabetes Care 39 (Supplement 1) S52-S59. (https://doi. org/10.2337/dc16-s010)

Adaramoye OA \& Lawal SO 2014 Effect of kolaviron, a biflavonoid complex from Garcinia kola seeds, on the antioxidant, hormonal and spermatogenic indices of diabetic male rats. Andrologia 46 878-886. (https://doi.org/10.1111/and.12160)

Adaramoye O, Akanni O, Adesanoye O, Labo-Popoola O \& Olaremi O 2012 Evaluation of toxic effects of metformin hydrochloride and glibenclamide on some organs of male rats. Nigerian Journal of Physiological Sciences 27 137-144.

Adashi EY, Hsueh AJ \& Yen SS 1981 Insulin enhancement of luteinizing hormone and follicle-stimulating hormone release by cultured pituitary cells. Endocrinology 108 1441-1449. (https://doi.org/10.1210/endo108-4-1441)

Agbaje IM, Rogers DA, McVicar CM, McClure N, Atkinson AB, Mallidis C \& Lewis SE 2007 Insulin dependant diabetes mellitus: implications for male reproductive function. Human Reproduction 22 1871-1877. (https://doi.org/10.1093/humrep/dem077)

Ahangarpour A, Oroojan AA \& Heidari H 2014 Effects of exendin-4 on male reproductive parameters of $d$-galactose induced aging mouse model. World Journal of Men's Health 32 176-183. (https://doi. org/10.5534/wjmh.2014.32.3.176)

Ahmed RG 2005 The physiological and biochemical effects of diabetes on the balance between oxidative stress and antioxidant defense system. Medical Journal of Islamic World Academy of Sciences 15 31-42.

Ahn TY, Park JK, Lee SW, Hong JH, Park NC, Kim JJ, Park K, Park H \& Hyun JS 2007 Prevalence and risk factors for erectile dysfunction in Korean men: results of an epidemiological study. Journal of Sexual Medicine 41269 1276. (https://doi.org/10.1111/j.1743-6109.2007.00554.x) 
Alberti KG \& Zimmet PZ 1998 Definition, diagnosis and classification of diabetes mellitus and its complications. Part 1: diagnosis and classification of diabetes mellitus provisional report of a WHO consultation. Diabetic Medicine 15 539-553. (https://doi.org/10.1002/ (SICI)1096-9136(199807)15:7<539::AID-DIA668>3.0.CO;2-S)

Alves MG, Socorro S, Silva J, Barros A, Sousa M, Cavaco JE \& Oliveira PF 2012 In vitro cultured human Sertoli cells secrete high amounts of acetate that is stimulated by 17 beta-estradiol and suppressed by insulin deprivation. Biochimica et Biophysica Acta 1823 1389-1394. (https:// doi.org/10.1016/j.bbamcr.2012.06.002)

Alves MG, Martins AD, Vaz CV, Correia S, Moreira PI, Oliveira PF \& Socorro S 2014 Metformin and male reproduction: effects on Sertoli cell metabolism. British Journal of Pharmacology 171 1033-1042. (https:// doi.org/10.1111/bph.12522)

Amaral S \& Ramalho-Santos J 2014 Free Radical Biology and Reproductive Health in Diabetes. Berlin: Springer.

Amaral S, Moreno AJ, Santos MS, Seica R \& Ramalho-Santos J 2006 Effects of hyperglycemia on sperm and testicular cells of Goto-Kakizaki and streptozotocin-treated rat models for diabetes. Theriogenology $\mathbf{6 6}$ 2056-2067. (https://doi.org/10.1016/j.theriogenology.2006.06.006)

Amaral S, Mota PC, Lacerda B, Alves M, Pereira Mde L, Oliveira PJ \& Ramalho-Santos J 2009 Testicular mitochondrial alterations in untreated streptozotocin-induced diabetic rats. Mitochondrion 9 41-50. (https:// doi.org/10.1016/j.mito.2008.11.005)

Aquila S, Gentile M, Middea E, Catalano S \& Ando S 2005 Autocrine regulation of insulin secretion in human ejaculated spermatozoa. Endocrinology 146 552-557. (https://doi.org/10.1210/en.2004-1252)

Aquila S, Bonofiglio D, Gentile M, Middea E, Gabriele S, Belmonte M, Catalano S, Pellegrino M \& Ando S 2006 Peroxisome proliferatoractivated receptor (PPAR)gamma is expressed by human spermatozoa: its potential role on the sperm physiology. Journal of Cellular Physiology 209 977-986. (https://doi.org/10.1002/jcp.20807)

Arikawe AP, Daramola AO, Odofin AO \& Obika LF 2006 Alloxan-induced and insulin-resistant diabetes mellitus affect semen parameters and impair spermatogenesis in male rats. African Journal of Reproductive Health 10 106-113. (https://doi.org/10.2307/30032477)

Ashcroft FM 1996 Mechanisms of the glycaemic effects of sulfonylureas. Hormone and Metabolic Research 28 456-463. (https://doi. org/10.1055/s-2007-979837)

Ashcroft FM \& Gribble FM 1998 Correlating structure and function in ATPsensitive K+ channels. Trends in Neurosciences 21 288-294. (https://doi. org/10.1016/S0166-2236(98)01225-9)

Attia SM, Helal GK \& Alhaider AA 2009 Assessment of genomic instability in normal and diabetic rats treated with metformin. Chemico-Biological Interactions 180 296-304. (https://doi.org/10.1016/j.cbi.2009.03.001)

Ayuob NN, Murad HA \& Ali SS 2015 Impaired expression of sex hormone receptors in male reproductive organs of diabetic rat in response to oral antidiabetic drugs. Folia Histochemica et Cytobiologica 53 35-48. (https://doi.org/10.5603/FHC.a2015.0005)

Baccetti B, La Marca A, Piomboni P, Capitani S, Bruni E, Petraglia F \& De Leo V 2002 Insulin-dependent diabetes in men is associated with hypothalamo-pituitary derangement and with impairment in semen quality. Human Reproduction 17 2673-2677. (https://doi.org/10.1093/ humrep/17.10.2673)

Bailey CJ \& Turner RC 1996 Metformin. New England Journal of Medicine 334 574-579. (https://doi.org/10.1056/NEJM199602293340906)

Baker J, Hardy MP, Zhou J, Bondy C, Lupu F, Bellve AR \& Efstratiadis A 1996 Effects of an Igf1 gene null mutation on mouse reproduction. Molecular Endocrinology 10 903-918. (https://doi.org/10.1210/me.10.7.903)

Ballester J, Munoz MC, Dominguez J, Rigau T, Guinovart JJ \& RodriguezGil JE 2004 Insulin-dependent diabetes affects testicular function by FSH- and LH-linked mechanisms. Journal of Andrology 25 706-719. (https://doi.org/10.1002/j.1939-4640.2004.tb02845.x)

Bansal TC, Guay AT, Jacobson J, Woods BO \& Nesto RW 2005 Incidence of metabolic syndrome and insulin resistance in a population with organic erectile dysfunction. Journal of Sexual Medicine 2 96-103. (https://doi. org/10.1111/j.1743-6109.2005.20120.x)

Bartak V, Josifko M \& Horackova M 1975 Juvenile diabetes and human sperm quality. International Journal of Fertility 20 30-32.

Basit A, Riaz M \& Fawwad A 2012 Glimepiride: evidence-based facts, trends, and observations (GIFTS). Vascular Health and Risk Management 8 463-472. (https://doi.org/10.2147/VHRM.S33194)
Bener A, Al-Ansari AA, Zirie M \& Al-Hamaq AO 2009 Is male fertility associated with type 2 diabetes mellitus? International Urology and Nephrology 41 777-784. (https://doi.org/10.1007/s11255-009-9565-6)

Benitez A \& Perez Diaz J 1985 Effect of streptozotocin-diabetes and insulin treatment on regulation of Leydig cell function in the rat. Hormone and Metabolic Research 17 5-7. (https://doi.org/10.1055/s-2007-1013433)

Berger J \& Moller DE 2002 The mechanisms of action of PPARs. Annual Review of Medicine 53 409-435. (https://doi.org/10.1146/annurev. med.53.082901.104018)

Bertoldo MJ, Faure M, Dupont J \& Froment P 2014 Impact of metformin on reproductive tissues: an overview from gametogenesis to gestation. Annals of Translational Medicine 255.

Bhattacharya N, Dufour JM, Vo MN, Okita J, Okita R \& Kim KH 2005 Differential effects of phthalates on the testis and the liver. Biology of Reproduction 72 745-754. (https://doi.org/10.1095/ biolreprod.104.031583)

Boberg J, Metzdorff S, Wortziger R, Axelstad M, Brokken L, Vinggaard AM, Dalgaard M \& Nellemann C 2008 Impact of diisobutyl phthalate and other PPAR agonists on steroidogenesis and plasma insulin and leptin levels in fetal rats. Toxicology 250 75-81. (https://doi.org/10.1016/j. tox.2008.05.020)

Borland K, Mita M, Oppenheimer CL, Blinderman LA, Massague J, Hall PF \& Czech MP 1984 The actions of insulin-like growth factors I and II on cultured Sertoli cells. Endocrinology 114 240-246. (https://doi. org/10.1210/endo-114-1-240)

Braissant O, Foufelle F, Scotto C, Dauca M \& Wahli W 1996 Differential expression of peroxisome proliferator-activated receptors (PPARs): tissue distribution of PPAR-alpha, -beta, and -gamma in the adult rat. Endocrinology 137 354-366. (https://doi.org/10.1210/ endo.137.1.8536636)

Brownlee M 2005 The pathobiology of diabetic complications: a unifying mechanism. Diabetes 54 1615-1625. (https://doi.org/10.2337/ diabetes.54.6.1615)

Bruning JC, Gautam D, Burks DJ, Gillette J, Schubert M, Orban PC, Klein R, Krone W, Muller-Wieland D \& Kahn CR 2000 Role of brain insulin receptor in control of body weight and reproduction. Science 289 2122-2125. (https://doi.org/10.1126/science.289.5487.2122)

Bucholtz DC, Chiesa A, Pappano WN, Nagatani S, Tsukamura H, Maeda KI \& Foster DL 2000 Regulation of pulsatile luteinizing hormone secretion by insulin in the diabetic male lamb. Biology of Reproduction 62 1248-1255. (https://doi.org/10.1095/biolreprod62.5.1248)

Burcelin R, Thorens B, Glauser M, Gaillard RC \& Pralong FP 2003 Gonadotropin-releasing hormone secretion from hypothalamic neurons: stimulation by insulin and potentiation by leptin. Endocrinology $\mathbf{1 4 4}$ 4484-4491. (https://doi.org/10.1210/en.2003-0457)

Burke MA, Mutharasan RK \& Ardehali H 2008 The sulfonylurea receptor, an atypical ATP-binding cassette protein, and its regulation of the KATP channel. Circulation Research 102 164-176. (https://doi.org/10.1161/ CIRCRESAHA.107.165324)

Burnicka-Turek O, Mohamed BA, Shirneshan K, Thanasupawat T, Hombach-Klonisch S, Klonisch T \& Adham IM 2012 INSL5-deficient mice display an alteration in glucose homeostasis and an impaired fertility. Endocrinology 153 4655-4665. (https://doi.org/10.1210/ en.2012-1161)

Cameron DF, Murray FT \& Drylie DD 1985 Interstitial compartment pathology and spermatogenic disruption in testes from impotent diabetic men. Anatomical Record 213 53-62. (https://doi.org/10.1002/ ar.1092130108)

Carpino A, Rago V, Guido C, Casaburi I \& Aquila S 2010 Insulin and IR-beta in pig spermatozoa: a role of the hormone in the acquisition of fertilizing ability. International Journal of Andrology 33 554-562. (https://doi.org/10.1111/j.1365-2605.2009.00971.x)

Ceriello A, Mercuri F, Quagliaro L, Assaloni R, Motz E, Tonutti L \& Taboga C 2001 Detection of nitrotyrosine in the diabetic plasma: evidence of oxidative stress. Diabetologia 44 834-838. (https://doi. org/10.1007/s001250100529)

Charles B, Norris R, Xiao X \& Hague W 2006 Population pharmacokinetics of metformin in late pregnancy. Therapeutic Drug Monitoring 28 67-72. (https://doi.org/10.1097/01.ftd.0000184161.52573.0e)

Charreau EH, Calvo JC, Tesone M, de Souza Valle LB \& Baranao JL 1978 Insulin regulation of Leydig cell luteinizing hormone receptors. Journal of Biological Chemistry $2532504-2506$. 
Choi WS, Kwon OS, Cho SY, Paick JS \& Kim SW 2015 Effect of chronic administration of PDE5 combined with glycemic control on erectile function in streptozotocin-induced diabetic rats. Journal of Sexual Medicine 12 600-610. (https://doi.org/10.1111/jsm.12752)

Couto JA, Saraiva KL, Barros CD, Udrisar DP, Peixoto CA, Vieira JS, Lima MC, Galdino SL, Pitta IR \& Wanderley MI 2010 Effect of chronic treatment with Rosiglitazone on Leydig cell steroidogenesis in rats: in vivo and ex vivo studies. Reproductive Biology and Endocrinology 813. (https://doi.org/10.1186/1477-7827-8-13)

Cryer PE 2008 The barrier of hypoglycemia in diabetes. Diabetes $\mathbf{5 7}$ 3169-3176. (https://doi.org/10.2337/db08-1084)

Cuypers J, Mathieu C \& Benhalima K 2013 SGLT2-inhibitors: a novel class for the treatment of type 2 diabetes introduction of SGLT2-inhibitors in clinical practice. Acta Clinica Belgica 68 287-293. (https://doi. org/10.2143/ACB.3349)

Dabrowski M, Wahl P, Holmes WE \& Ashcroft FM 2001 Effect of repaglinide on cloned beta cell, cardiac and smooth muscle types of ATP-sensitive potassium channels. Diabetologia 44 747-756. (https://doi.org/10.1007/ s001250051684)

Dallinga-Thie GM \& Nieuwdorp M 2015 glp1, an important regulator of intestinal lipid metabolism. Arteriosclerosis, Thrombosis, and Vascular Biology 35 1048-1049. (https://doi.org/10.1161/ATVBAHA.115.305479)

Delfino M, Imbrogno N, Elia J, Capogreco F \& Mazzilli F 2007 Prevalence of diabetes mellitus in male partners of infertile couples. Minerva Urologica e Nefrologica 59 131-135.

Desvergne B \& Wahli W 1999 Peroxisome proliferator-activated receptors: nuclear control of metabolism. Endocrine Reviews 20 649-688. (https:/ doi.org/10.1210/er.20.5.649)

Dias TR, Rato L, Martins AD, Simoes VL, Jesus TT, Alves MG \& Oliveira PF 2013 Insulin deprivation decreases caspase-dependent apoptotic signaling in cultured rat sertoli cells. ISRN Urology 2013970370.

Dong Q, Lazarus RM, Wong LS, Vellios M \& Handelsman DJ 1991 Pulsatile $\mathrm{LH}$ secretion in streptozotocin-induced diabetes in the rat. Journal of Endocrinology 131 49-55. (https://doi.org/10.1677/joe.0.1310049)

El-Atat F, McFarlane SI \& Sowers JR 2004 Diabetes, hypertension, and cardiovascular derangements: pathophysiology and management. Current Hypertension Reports 6 215-223. (https://doi.org/10.1007/ s11906-004-0072-y)

El-Kaissi S \& Sherbeeni S 2011 Pharmacological management of type 2 diabetes mellitus: an update. Current Diabetes Reviews 7 392-405. (https://doi.org/10.2174/157339911797579160)

Emilien G, Maloteaux JM \& Ponchon M 1999 Pharmacological management of diabetes: recent progress and future perspective in daily drug treatment. Pharmacology and Therapeutics 81 37-51. (https://doi. org/10.1016/S0163-7258(98)00034-5)

Erkkila K, Aito H, Aalto K, Pentikainen V \& Dunkel L 2002 Lactate inhibits germ cell apoptosis in the human testis. Molecular Human Reproduction 8 109-117. (https://doi.org/10.1093/molehr/8.2.109)

Evans RM, Barish GD \& Wang YX 2004 PPARs and the complex journey to obesity. Nature Medicine 10 355-361. (https://doi.org/10.1038/nm1025)

Ferreira C, Sousa M, Rabaca A, Oliveira PF, Alves MG \& Sa R 2015 Impact of metformin on male reproduction. Current Pharmaceutical Design $\mathbf{2 1}$ 3621-3633. (https://doi.org/10.2174/1381612821666150710150041)

Fontoura P, Cardoso MC, Erthal-Martins MC, Werneck C, Sartorio C \& Ramos CF 2014 The effects of liraglutide on male fertility: a case report. Reproductive BioMedicine Online 29 644-646. (https://doi. org/10.1016/j.rbmo.2014.07.009)

Fukumoto Y, Yoshida M, Dokita S, Kamai T, Weiss RM \& Latifpour J 1993 The reversal effect of insulin on diabetes-induced alterations in beta adrenergic and muscarinic receptors in rat prostate. Journal of Urology 149 1602-1606. (https://doi.org/10.1016/S0022-5347(17)36459-5)

Furnsinn C, Nowotny P, Brunmair B, Gras F, Roden M, WaldhausI W \& Vierhapper H 2002 Thiazolidinediones influence plasma steroids of male obese Zucker rats. Endocrinology 143 327. (https://doi. org/10.1210/endo.143.1.8689)

Garg A \& Grundy SM 1994 Cholestyramine therapy for dyslipidemia in non-insulin-dependent diabetes mellitus. A short-term, double-blind, crossover trial. Annals of Internal Medicine 121 416-422. (https://doi. org/10.7326/0003-4819-121-6-199409150-00004)

Gasic S, Bodenburg Y, Nagamani M, Green A \& Urban RJ 1998 Troglitazone inhibits progesterone production in porcine granulosa cells. Endocrinology 139 4962-4966. (https://doi.org/10.1210/ endo.139.12.6385)

Gitlin N, Julie NL, Spurr CL, Lim KN \& Juarbe HM 1998 Two cases of severe clinical and histologic hepatotoxicity associated with troglitazone. Annals of Internal Medicine 129 36-38. (https://doi.org/10.7326/00034819-129-1-199807010-00008)

Gomez O, Ballester B, Romero A, Arnal E, Almansa I, Miranda M, Mesonero JE \& Terrado J 2009 Expression and regulation of insulin and the glucose transporter GLUT8 in the testes of diabetic rats. Hormone and Metabolic Research 41 343-349. (https://doi. org/10.1055/s-0028-1128146)

Gomez-Hernandez A, Beneit N, Diaz-Castroverde S \& Escribano O 2016 Differential role of adipose tissues in obesity and related metabolic and vascular complications. International Journal of Endocrinology $\mathbf{2 0 1 6}$ 1216783.

Gondos B \& Bevier W 1995 Effect of insulin on testicular alterations in the nonobese diabetic mouse. Annals of Clinical and Laboratory Science 25 272-277.

Gorus FK \& Pipeleers DG 1986 Glucose metabolism in human spermatozoa: lack of insulin effects and dissociation from alloxan handling. Journal of Cellular Physiology 127 261-266. (https://doi. org/10.1002/jcp.1041270211)

Greenfield JR \& Campbell LV 2006 Relationship between inflammation, insulin resistance and type 2 diabetes: 'cause or effect'? Current Diabetes Reviews 2 195-211. (https://doi.org/10.2174/157339906776818532)

Griffeth RJ, Carretero J \& Burks DJ 2013 Insulin receptor substrate 2 is required for testicular development. PLOS ONE 8 e62103. (https://doi. org/10.1371/journal.pone.0062103)

Gumieniczek A, Hopkala H \& Zabek A 2008 Protective effects of a PPARgamma agonist pioglitazone on anti-oxidative system in testis of diabetic rabbits. Pharmazie 63 377-378.

Gumieniczek A, Komsta L \& Chehab MR 2011 Effects of two oral antidiabetics, pioglitazone and repaglinide, on aconitase inactivation, inflammation and oxidative/nitrosative stress in tissues under alloxaninduced hyperglycemia. European Journal of Pharmacology 659 89-93. (https://doi.org/10.1016/j.ejphar.2010.12.039)

Gupta V 2013 Glucagon-like peptide-1 analogues: an overview. Indian Journal of Endocrinology and Metabolism 17 413-421. (https://doi. org/10.4103/2230-8210.111625)

Handelsman DJ, Conway AJ, Boylan LM, Yue DK \& Turtle JR 1985 Testicular function and glycemic control in diabetic men. A controlled study. Andrologia 17 488-496. (https://doi.org/10.1111/j.1439-0272.1985. tb01047.x)

Hauner H 2002 The mode of action of thiazolidinediones. Diabetes/ Metabolism Research and Reviews 18 (Supplement 2) S10-S15. (https:// doi.org/10.1002/dmrr.249)

Herrine SK \& Choudhary C 1999 Severe hepatotoxicity associated with troglitazone. Annals of Internal Medicine 130 163-164. (https://doi. org/10.7326/0003-4819-130-2-199901190-00021)

Hibi H, Ohori T \& Yamada Y 2011 DPP-IV inhibitor may affect spermatogenesis. Diabetes Research and Clinical Practice 93 e74-e75. (https://doi.org/10.1016/j.diabres.2011.04.022)

Hicks J, Rojas L \& Rosado A 1973 Insulin regulation of spermatozoa metabolism. Endocrinology 92 833-839. (https://doi.org/10.1210/endo92-3-833)

Hoogwerf BJ, Doshi KB \& Diab D 2008 Pramlintide, the synthetic analogue of amylin: physiology, pathophysiology, and effects on glycemic control, body weight, and selected biomarkers of vascular risk. Vascular Health and Risk Management 4 355-362. (https://doi.org/10.2147/VHRM. S1978)

Hurtado de Catalfo GE \& De Gomez Dumm IN 1998 Lipid dismetabolism in Leydig and Sertoli cells isolated from streptozotocin-diabetic rats. International Journal of Biochemistry and Cell Biology 30 1001-1010. (https://doi.org/10.1016/S1357-2725(98)00055-7)

Hutson JC, Stocco DM, Campbell GT \& Wagoner J 1983 Sertoli cell function in diabetic, insulin-treated diabetic, and semi-starved rats. Diabetes 32 112-116. (https://doi.org/10.2337/diab.32.2.112)

Hvidberg A, Nielsen MT, Hilsted J, Orskov C \& Holst JJ 1994 Effect of glucagon-like peptide-1 (proglucagon 78-107 amide) on hepatic glucose production in healthy man. Metabolism 43 104-108. (https:// doi.org/10.1016/0026-0495(94)90164-3) 
Ibabe A, Bilbao E \& Cajaraville MP 2005 Expression of peroxisome proliferator-activated receptors in zebrafish (Danio rerio) depending on gender and developmental stage. Histochemistry and Cell Biology 123 75-87. (https://doi.org/10.1007/s00418-004-0737-2)

IDF (International Diabetes Federation) 2015 IDF Diabetes Atlas, Seventh Edition.

Ikeda K, Wada Y, Foster HE Jr, Wang Z, Weiss RM \& Latifpour J 2000 Experimental diabetes-induced regression of the rat prostate is associated with an increased expression of transforming growth factorbeta. Journal of Urology 164 180-185. (https://doi.org/10.1016/S00225347(05)67491-5)

Jackson JE \& Bressler R 1981 Clinical pharmacology of sulphonylurea hypoglycaemic agents: part 2. Drugs 22 295-320. (https://doi. org/10.2165/00003495-198122040-00003)

Janbon M, Chaptal J, Uedel A \& Schaap J 1942 Accidents hypoglycémiques graves par un sulfamidothiodiazol (le VK 57 ou 2254 RP). Montepellier Medicine 441 21-22.

Ji L, Ma J, Li H, Mansfield TA, T'Joen C L, Iqbal N, Ptaszynska A \& List JF 2014 Dapagliflozin as monotherapy in drug-naive Asian patients with type 2 diabetes mellitus: a randomized, blinded, prospective phase III study. Clinical Therapeutics 36 84.e9-100.e9. (https://doi.org/10.1016/j. clinthera.2013.11.002)

Kar P \& Holt RI 2008 The effect of sulphonylureas on the microvascular and macrovascular complications of diabetes. Cardiovascular Drugs and Therapy 22 207-213. (https://doi.org/10.1007/s10557-008-6090-2)

Karl AF \& Griswold MD 1980 Actions of insulin and vitamin A on Sertoli cells. Biochemical Journal 186 1001-1003. (https://doi.org/10.1042/ bj1861001)

Kempna P, Hofer G, Mullis PE \& Fluck CE 2007 Pioglitazone inhibits androgen production in $\mathrm{NCl}-\mathrm{H} 295 \mathrm{R}$ cells by regulating gene expression of CYP17 and HSD3B2. Molecular Pharmacology 71 787-798. (https:// doi.org/10.1124/mol.106.028902)

Khan S, Teerds K \& Dorrington J 1992 Growth factor requirements for DNA synthesis by Leydig cells from the immature rat. Biology of Reproduction 46 335-341. (https://doi.org/10.1095/biolreprod46.3.335)

Kianifard D, Sadrkhanlou RA \& Hasanzadeh S 2011 The histological, histomorphometrical and histochemical changes of testicular tissue in the metformin treated and untreated streptozotocin-induced adult diabetic rats. Veterinary Research Forum 2 13-24.

Kianifard D, Sadrkhanlou RA \& Hasanzadeh S 2012 The ultrastructural changes of the sertoli and leydig cells following streptozotocin induced diabetes. Iranian Journal of Basic Medical Sciences 15 623-635.

Kim ST \& Moley KH 2008 Paternal effect on embryo quality in diabetic mice is related to poor sperm quality and associated with decreased glucose transporter expression. Reproduction 136 313-322. (https://doi. org/10.1530/REP-08-0167)

Kim YW, Kim JY, Park YH, Park SY, Won KC, Choi KH, Huh JY \& Moon KH 2006 Metformin restores leptin sensitivity in high-fat-fed obese rats with leptin resistance. Diabetes 55 716-724. (https://doi.org/10.2337/ diabetes.55.03.06.db05-0917)

Kovanecz I, Ferrini MG, Vernet D, Nolazco G, Rajfer J \& GonzalezCadavid NF 2006 Pioglitazone prevents corporal veno-occlusive dysfunction in a rat model of type 2 diabetes mellitus. BJU International 98 116-124. (https://doi.org/10.1111/j.1464-410X.2006.06268.x)

Kovo M, Haroutiunian S, Feldman N, Hoffman A \& Glezerman M 2008 Determination of metformin transfer across the human placenta using a dually perfused ex vivo placental cotyledon model. European Journal of Obstetrics and Gynecology and Reproductive Biology 136 29-33. (https://doi.org/10.1016/j.ejogrb.2007.01.013)

Kumar N, Jain S, Gupta A \& Tiwary AK 2008 Spermicidal activity of sulfonylureas and meglitinide analogues: role of intrasperm $\mathrm{Ca} 2+$ elevation. Journal of Pharmacy and Pharmacology $60323-330$. (https:// doi.org/10.1211/jpp.60.3.0007)

Kyathanahalli C, Bangalore S, Hanumanthappa K \& Muralidhara 2014 Experimental diabetes-induced testicular damage in prepubertal rats. Journal of Diabetes 6 48-59. (https://doi.org/10.1111/1753-0407.12068)

La Vignera S, Calogero AE, Condorelli R, Lanzafame F, Giammusso B \& Vicari E 2009a Andrological characterization of the patient with diabetes mellitus. Minerva Endocrinologica 34 1-9.

La Vignera S, Vicari E, Calogero AE, Condorelli R \& Lanzafame F 2009b Diabetes, oxidative stress and its impact on male fertility. Journal of Andrological Sciences 16 42-46.
La Vignera S, Condorelli RA, Vicari E, D'Agata R \& Calogero AE 2011 Seminal vesicles and diabetic neuropathy: ultrasound evaluation in patients with couple infertility and different levels of glycaemic control. Asian Journal of Andrology 13 872-876. (https://doi.org/10.1038/ aja.2011.47)

La Vignera S, Condorelli RA, Di Mauro M, Lo Presti D, Mongioi LM, Russo G \& Calogero AE 2015 Reproductive function in male patients with type 1 diabetes mellitus. Andrology 3 1082-1087. (https://doi. org/10.1111/andr.12097)

Labazi H, Wynne BM, Tostes R \& Webb RC 2013 Metformin treatment improves erectile function in an angiotensin II model of erectile dysfunction. Journal of Sexual Medicine 10 2154-2164. (https://doi. org/10.1111/jsm.12245)

Lampiao F \& du Plessis SS 2008 Insulin and leptin enhance human sperm motility, acrosome reaction and nitric oxide production. Asian Journal of Andrology 10 799-807. (https://doi.org/10.1111/j.17457262.2008.00421.x)

Landgraf R 2000 Meglitinide analogues in the treatment of type 2 diabetes mellitus. Drugs and Aging 17 411-425. (https://doi. org/10.2165/00002512-200017050-00007)

Lebovitz HE 2001 Oral therapies for diabetic hyperglycemia. Endocrinology Metabolism Clinics of North America 30 909-933. (https://doi. org/10.1016/S0889-8529(05)70221-8)

Lehmann JM, Moore LB, Smith-Oliver TA, Wilkison WO, Willson TM \& Kliewer SA 1995 An antidiabetic thiazolidinedione is a high affinity ligand for peroxisome proliferator-activated receptor gamma (PPAR gamma). Journal of Biological Chemistry 270 12953-12956. (https://doi. org/10.1074/jbc.270.22.12953)

Lin T, Haskell J, Vinson N \& Terracio L 1986 Characterization of insulin and insulin-like growth factor I receptors of purified Leydig cells and their role in steroidogenesis in primary culture: a comparative study. Endocrinology 119 1641-1647. (https://doi.org/10.1210/endo-119-41641)

Lochhead PA, Salt IP, Walker KS, Hardie DG \& Sutherland C 2000 5-Aminoimidazole - carboxamide riboside mimics the effects of insulin on the expression of the 2 key gluconeogenic genes PEPCK and glucose-6-phosphatase. Diabetes 49 896-903. (https://doi.org/10.2337/ diabetes.49.6.896)

Lopez-Alvarenga JC, Zarinan T, Olivares A, Gonzalez-Barranco J, Veldhuis JD \& Ulloa-Aguirre A 2002 Poorly controlled type I diabetes mellitus in young men selectively suppresses luteinizing hormone secretory burst mass. Journal of Clinical Endocrinology and Metabolism 87 5507-5515. (https://doi.org/10.1210/jc.2002-020803)

Lybaert P, Vanbellinghen AM, Quertinmont E, Petein M, Meuris S \& Lebrun P 2008 KATP channel subunits are expressed in the epididymal epithelium in several mammalian species. Biology of Reproduction $\mathbf{7 9}$ 253-261. (https://doi.org/10.1095/biolreprod.107.064659)

Malaisse WJ 1995 Stimulation of insulin release by non-sulfonylurea hypoglycemic agents: the meglitinide family. Hormone and Metabolic Research 27 263-266. (https://doi.org/10.1055/s-2007-979955)

Malaisse WJ 2003 Pharmacology of the meglitinide analogs: new treatment options for type 2 diabetes mellitus. Treatments in Endocrinology 2 401-414. (https://doi.org/10.2165/00024677-200302060-00004)

Mangoli E, Talebi AR, Anvari M \& Pourentezari M 2013 Effects of experimentally-induced diabetes on sperm parameters and chromatin quality in mice. International Journal of Reproductive BioMedicine $\mathbf{1 1}$ 53-60.

Mansour M, Coleman E, Dennis J, Akingbemi B, Schwartz D, Braden T, Judd R, Plaisance E, Stewart LK \& Morrison E 2009 Activation of PPARgamma by rosiglitazone does not negatively impact male sex steroid hormones in diabetic rats. PPAR Research 2009101857.

Marfella R, Quagliaro L, Nappo F, Ceriello A \& Giugliano D 2001 Acute hyperglycemia induces an oxidative stress in healthy subjects. Journal of Clinical Investigation 108 635-636. (https://doi.org/10.1172/ JCI13727)

Marquis JK, Dagher R \& Jones M 2004 Dietary administration of colesevelam hydrochloride does not affect fertility or reproductive performance in rats. International Journal of Toxicology 23 357-367. (https://doi.org/10.1080/10915810490902010)

Mauvais-Jarvis F 2016 Role of sex steroids in beta cell function, growth, and survival. Trends in Endocrinology and Metabolism 27 844-855. (https://doi.org/10.1016/j.tem.2016.08.008) 
Melnik BC \& Schmitz G 2014 Metformin: an inhibitor of mTORC1 signaling. Journal of Endocrinology, Diabetes and Obesity 21029.

Meneses MJ, Bernardino RL, Sa R, Silva J, Barros A, Sousa M, Silva BM, Oliveira PF \& Alves MG 2016 Pioglitazone increases the glycolytic efficiency of human Sertoli cells with possible implications for spermatogenesis. International Journal of Biochemistry and Cell Biology 79 52-60. (https://doi.org/10.1016/j.biocel.2016.08.011)

Miller BR, Nguyen H, Hu CJ, Lin C \& Nguyen QT 2014 New and emerging drugs and targets for type 2 diabetes: reviewing the evidence. American Health and Drug Benefits 7 452-463.

Morrison JF, Dhanasekaran S, Sheen R, Frampton CM \& Mensah-Brown E 2006 The effect of streptozotocin-induced diabetes on the rat seminal vesicle: a possible pathophysiological basis for disorders of ejaculation. Annals of the New York Academy of Sciences 1084 267-279. (https:// doi.org/10.1196/annals.1372.013)

Mulholland J, Mallidis C, Agbaje I \& McClure N 2011 Male diabetes mellitus and assisted reproduction treatment outcome. Reproductive BioMedicine Online $22 \quad 215-219 . \quad$ (https://doi.org/10.1016/j. rbmo.2010.10.005)

Munoz-Garay C, De la Vega-Beltran JL, Delgado R, Labarca P, Felix R \& Darszon A 2001 Inwardly rectifying $\mathrm{K}(+)$ channels in spermatogenic cells: functional expression and implication in sperm capacitation. Developmental Biology 234 261-274. (https://doi.org/10.1006/ dbio.2001.0196)

Muoio DM \& Newgard CB 2008 Mechanisms of disease:Molecular and metabolic mechanisms of insulin resistance and beta-cell failure in type 2 diabetes. Nature Reviews Molecular Cell Biology 9 193-205. (https:// doi.org/10.1038/nrm2327)

Murray FT, Orth J, Gunsalus G, Weisz J, Li JB, Jefferson LS, Musto NA \& Bardin CW 1981 The pituitary-testicular axis in the streptozotocin diabetic male rat: evidence for gonadotroph, Sertoli cell and Leydig cell dysfunction. International Journal of Andrology 4 265-280. (https://doi. org/10.1111/j.1365-2605.1981.tb00710.x)

Nakayama Y, Yamamoto T \& Abe SI 1999 IGF-I, IGF-II and insulin promote differentiation of spermatogonia to primary spermatocytes in organ culture of newt testes. International Journal of Developmental Biology 43 343-347.

Navarro-Casado L, Juncos-Tobarra MA, Chafer-Rudilla M, de Onzono LI, Blazquez-Cabrera JA \& Miralles-Garcia JM 2010 Effect of experimental diabetes and STZ on male fertility capacity. Study in rats. Journal of Andrology 31 584-592. (https://doi.org/10.2164/jandrol.108.007260)

Nef S, Verma-Kurvari S, Merenmies J, Vassalli JD, Efstratiadis A, Accili D \& Parada LF 2003 Testis determination requires insulin receptor family function in mice. Nature 426 291-295. (https://doi.org/10.1038/ nature02059)

Nelli GB, Anand Solomon K \& Kilari EK 2013 Antidiabetic effect of alphamangostin and its protective role in sexual dysfunction of streptozotocin induced diabetic male rats. Systems Biology in Reproductive Medicine 59 319-328. (https://doi.org/10.3109/19396368.2013.820369)

Neuschwander-Tetri BA, Isley WL, Oki JC, Ramrakhiani S, Quiason SG, Phillips NJ \& Brunt EM 1998 Troglitazone-induced hepatic failure leading to liver transplantation. A case report. Annals of Internal Medicine $\mathbf{1 2 9}$ 38-41. (https://doi.org/10.7326/0003-4819-129-1-199807010-00009)

Niven MJ, Hitman GA \& Badenoch DF 1995 A study of spermatozoal motility in type 1 diabetes mellitus. Diabetic Medicine 12 921-924. (https://doi.org/10.1111/j.1464-5491.1995.tb00397.x)

Oliveira PF, Alves MG, Rato L, Laurentino S, Silva J, Sa R, Barros A, Sousa M, Carvalho RA, Cavaco JE et al. 2012 Effect of insulin deprivation on metabolism and metabolism-associated gene transcript levels of in vitro cultured human Sertoli cells. Biochimica et Biophysica Acta 1820 84-89. (https://doi.org/10.1016/j.bbagen.2011.11.006)

Oonk RB \& Grootegoed JA 1987 Identification of insulin receptors on rat Sertoli cells. Molecular and Cellular Endocrinology 49 51-62. (https:// doi.org/10.1016/0303-7207(87)90063-3)

Oonk RB, Grootegoed JA \& van der Molen HJ 1985 Comparison of the effects of insulin and follitropin on glucose metabolism by Sertoli cells from immature rats. Molecular and Cellular Endocrinology 42 39-48. (https://doi.org/10.1016/0303-7207(85)90005-X)

Orth JM, Murray FT \& Bardin CW 1979 Ultrastructural changes in Leydig cells of streptozotocin-induced diabetic rats. Anatomical Record 195 415-430. (https://doi.org/10.1002/ar.1091950302)
Padron RS, Dambay A, Suarez R \& Mas J 1984 Semen analyses in adolescent diabetic patients. Acta Diabetologica Latina 21 115-121. (https://doi.org/10.1007/BF02591100)

Panten U, Schwanstecher M \& Schwanstecher C 1996 Sulfonylurea receptors and mechanism of sulfonylurea action. Experimental and Clinical Endocrinology and Diabetes 104 1-9. (https://doi. org/10.1055/s-0029-1211414)

Paz G \& Homonnai ZT 1979 Leydig cell function in streptozotocin-induced diabetic rats. Experientia 35 1412-1413. (https://doi.org/10.1007/ BF01964042)

Penson DF, Wessells H, Cleary P, Rutledge BN \& Diabetes Control and Complications Trial/Epidemiology of Diabetes Interventions and Complications Research Group 2009 Sexual dysfunction and symptom impact in men with long-standing type 1 diabetes in the DCCT/ EDIC cohort. Journal of Sexual Medicine 6 1969-1978. (https://doi. org/10.1111/j.1743-6109.2009.01292.x)

Perez Diaz J, Benitez A \& Fernandez Galaz C 1982 Effect of streptozotocin diabetes on the pituitary-testicular axis in the rat. Hormone and Metabolic Research 14 479-482. (https://doi.org/10.1055/s-2007-1019052)

Pirwany IR, Yates RW, Cameron IT \& Fleming R 1999 Effects of the insulin sensitizing drug metformin on ovarian function, follicular growth and ovulation rate in obese women with oligomenorrhoea. Human Reproduction 14 2963-2968. (https://doi.org/10.1093/ humrep/14.12.2963)

Pitocco D, Zaccardi F, Di Stasio E, Romitelli F, Santini SA, Zuppi C \& Ghirlanda G 2010 Oxidative stress, nitric oxide, and diabetes. Review of Diabetic Studies 7 15-25. (https://doi.org/10.1900/RDS.2010.7.15)

Pitteloud N, Hardin M, Dwyer AA, Valassi E, Yialamas M, Elahi D \& Hayes FJ 2005a Increasing insulin resistance is associated with a decrease in Leydig cell testosterone secretion in men. Journal of Clinical Endocrinology and Metabolism 90 2636-2641. (https://doi.org/10.1210/ jc.2004-2190)

Pitteloud N, Mootha VK, Dwyer AA, Hardin M, Lee H, Eriksson KF, Tripathy D, Yialamas M, Groop L, Elahi D et al. 2005b Relationship between testosterone levels, insulin sensitivity, and mitochondrial function in men. Diabetes Care 28 1636-1642. (https://doi.org/10.2337/ diacare.28.7.1636)

Porte D Jr, Baskin DG \& Schwartz MW 2005 Insulin signaling in the central nervous system: a critical role in metabolic homeostasis and disease from C. elegans to humans. Diabetes 54 1264-1276. (https:// doi.org/10.2337/diabetes.54.5.1264)

Rabbani SI, Devi K \& Khanam S 2008 Effect of thiazolidinediones on the erythropoeitic and germinal cells in the male wistar rats. Clinical Medicine Oncology 2 423-429. (https://doi.org/10.4137/CMO.S423)

Rabbani SI, Devi K \& Khanam S 2009 Inhibitory effect of glimepiride on nicotinamide-streptozotocin induced nuclear damages and sperm abnormality in diabetic Wistar rats. Indian Journal of Experimental Biology 47 804-810.

Rabbani SI, Devi K \& Khanam S 2010a Pioglitazone, a PPAR-gamma ligand inhibited the nicotinamide-streptozotocin induced sperm abnormalities in type-2 diabetic Wistar rats. Pakistan Journal of Pharmaceutical Sciences 23 326-331.

Rabbani SI, Devi K \& Khanam S 2010b Protective role of glibenclamide against nicotinamide-streptozotocin induced nuclear damage in diabetic Wistar rats. Journal of Pharmacology and Pharmacotherapeutics 1 18-23. (https://doi.org/10.4103/0976-500X.64531)

Rama Raju GA, Jaya Prakash G, Murali Krishna K, Madan K, Siva Narayana T \& Ravi Krishna CH 2012 Noninsulin-dependent diabetes mellitus: effects on sperm morphological and functional characteristics, nuclear DNA integrity and outcome of assisted reproductive technique. Andrologia 44 (Supplement 1) 490-498. (https://doi.org/10.1111/j.14390272.2011.01213.x)

Rey-Valzacchi GJ, Costanzo PR, Finger LA, Layus AO, Gueglio GM, Litwak LE \& Knoblovits P 2012 Addition of metformin to sildenafil treatment for erectile dysfunction in eugonadal nondiabetic men with insulin resistance. A prospective, randomized, double-blind pilot study. Journal of Andrology 33 608-614. (https://doi.org/10.2164/ jandrol.111.013714)

Roessner C, Paasch U, Kratzsch J, Glander HJ \& Grunewald S 2012 Sperm apoptosis signalling in diabetic men. Reproductive BioMedicine Online 25 292-299. (https://doi.org/10.1016/j.rbmo.2012.06.004) 
Roglic G, Unwin N, Bennett PH, Mathers C, Tuomilehto J, Nag S, Connolly V \& King H 2005 The burden of mortality attributable to diabetes: realistic estimates for the year 2000. Diabetes Care 28 2130-2135. (https://doi.org/10.2337/diacare.28.9.2130)

Sadeghi A, Babazadeh D, Eghbal R \& Alyari Gavaher M 2013 Comparative appraisal of acarbose, pioglitazone and repaglinide on histopathology of testis in streptozotocin induced diabetic rats. International Journal of Fertility and Sterility 7 67-67.

Sainio-Pollanen S, Henriksen K, Parvinen M, Simell O \& Pollanen P 1997 Stage-specific degeneration of germ cells in the seminiferous tubules of non-obese diabetic mice. International Journal of Andrology 20 243-253. (https://doi.org/10.1046/j.1365-2605.1997.00061.x)

Saito M, Wada Y, Ikeda K, Wang Z, Foster HE Jr, Smith SD, Weiss RM \& Latifpour J 2000 Expression of endothelin receptor subtypes and their messenger RNAs in diabetic rat prostate: effect of insulin treatment. Molecular and Cellular Biochemistry 210 1-12. (https://doi. org/10.1023/A:1007041909477)

Sanguinetti RE, Ogawa K, Kurohmaru M \& Hayashi Y 1995 Ultrastructural changes in mouse Leydig cells after streptozotocin administration. Experimental Animals 44 71-73. (https://doi.org/10.1538/expanim.44.71)

Saucier J, Dube JY \& Tremblay RR 1981 Specific insulin binding sites in rat testis: characterization and variation. Endocrinology 109 2220-2225. (https://doi.org/10.1210/endo-109-6-2220)

Scarano WR, Messias AG, Oliva SU, Klinefelter GR \& Kempinas WG 2006 Sexual behaviour, sperm quantity and quality after shortterm streptozotocin-induced hyperglycaemia in rats. International Journal of Andrology 29 482-488. (https://doi.org/10.1111/j.13652605.2006.00682.x)

Schoeller EL, Albanna G, Frolova AI \& Moley KH 2012a Insulin rescues impaired spermatogenesis via the hypothalamic-pituitary-gonadal axis in Akita diabetic mice and restores male fertility. Diabetes $\mathbf{6 1}$ 1869-1878. (https://doi.org/10.2337/db11-1527)

Schoeller EL, Schon S \& Moley KH 2012b The effects of type 1 diabetes on the hypothalamic, pituitary and testes axis. Cell and Tissue Research $\mathbf{3 4 9}$ 839-847. (https://doi.org/10.1007/s00441-012-1387-7)

Scott J \& Poffenbarger PL 1979 Pharmacogenetics of tolbutamide metabolism in humans. Diabetes 28 41-51. (https://doi.org/10.2337/ diabetes.28.1.41)

Seethalakshmi L, Menon M \& Diamond D 1987 The effect of streptozotocininduced diabetes on the neuroendocrine-male reproductive tract axis of the adult rat. Journal of Urology 138 190-194. (https://doi.org/10.1016/ S0022-5347(17)43042-4)

Sehra D, Sehra S \& Sehra ST 2011 Sulfonylureas: do we need to introspect safety again? Expert Opinion on Drug Safety 10 851-861. (https://doi.or g/10.1517/14740338.2011.583234)

Seltzer HS 1980 Efficacy and safety of oral hypoglycemic agents. Annual Review of Medicine 31 261-272. (https://doi.org/10.1146/annurev. me.31.020180.001401)

Shabanpoor F, Separovic F \& Wade JD 2009 The human insulin superfamily of polypeptide hormones. Vitamins and Hormones $\mathbf{8 0} 1-31$. (https://doi. org/10.1016/s0083-6729(08)00601-8)

Shrilatha B \& Muralidhara 2007a Early oxidative stress in testis and epididymal sperm in streptozotocin-induced diabetic mice: its progression and genotoxic consequences. Reproductive Toxicology 23 578-587. (https://doi.org/10.1016/j.reprotox.2007.02.001)

Shrilatha B \& Muralidhara 2007b Occurrence of oxidative impairments, response of antioxidant defences and associated biochemical perturbations in male reproductive milieu in the Streptozotocindiabetic rat. International Journal of Andrology 30 508-518. (https://doi. org/10.1111/j.1365-2605.2007.00748.x)

Silvestroni L, Modesti A \& Sartori C 1992 Insulin-sperm interaction: effects on plasma membrane and binding to acrosome. Archives of Andrology 28 201-211. (https://doi.org/10.3109/01485019208987699)

Singh S, Malini T, Rengarajan S \& Balasubramanian K 2009 Impact of experimental diabetes and insulin replacement on epididymal secretory products and sperm maturation in albino rats. Journal of Cellular Biochemistry 108 1094-1101. (https://doi.org/10.1002/jcb.22337)

Skinner MK \& Griswold MD 1982 Secretion of testicular transferrin by cultured Sertoli cells is regulated by hormones and retinoids. Biology of Reproduction 27 211-221. (https://doi.org/10.1095/ biolreprod27.1.211)
Skliros NP, Vlachopoulos C \& Tousoulis D 2016 Treatment of diabetes: crossing to the other side. Hellenic Journal of Cardiology 57 304-310. (https://doi.org/10.1016/j.hjc.2016.07.002)

Sliwa L 1994 Effects of selected hormones on the motility of spermatozoa in the mouse vas deferens. Archives of Andrology 33 145-149. (https:// doi.org/10.3109/01485019408987817)

Soder O, Bang P, Wahab A \& Parvinen M 1992 Insulin-like growth factors selectively stimulate spermatogonial, but not meiotic, deoxyribonucleic acid synthesis during rat spermatogenesis. Endocrinology 131 2344-2350. (https://doi.org/10.1210/endo.131.5.1425434)

Song CJ, Yang ZJ, Tang QF \& Chen ZH 2015 Effects of sericin on the testicular growth hormone/insulin-like growth factor-1 axis in a rat model of type 2 diabetes. International Journal of Clinical and Experimental Medicine 8 10411-10419.

Soudamani S, Malini T \& Balasubramanian K 2005 Effects of streptozotocindiabetes and insulin replacement on the epididymis of prepubertal rats: histological and histomorphometric studies. Endocrine Research 31 81-98. (https://doi.org/10.1080/07435800500229193)

Staels B \& Fruchart JC 2005 Therapeutic roles of peroxisome proliferatoractivated receptor agonists. Diabetes 54 2460-2470. (https://doi. org/10.2337/diabetes.54.8.2460)

Steger RW \& Kienast SG 1990 Effect of continuous versus delayed insulin replacement on sex behavior and neuroendocrine function in diabetic male rats. Diabetes 39 942-948. (https://doi.org/10.2337/diab.39.8.942)

Stein SA, Lamos EM \& Davis SN 2013 A review of the efficacy and safety of oral antidiabetic drugs. Expert Opinion on Drug Safety 12 153-175. (https://doi.org/10.1517/14740338.2013.752813)

Sturgess NC, Ashford ML, Cook DL \& Hales CN 1985 The sulphonylurea receptor may be an ATP-sensitive potassium channel. Lancet 2 474-475. (https://doi.org/10.1016/S0140-6736(85)90403-9)

Sudha S, Valli G, Julie PM, Arunakaran J, Govindarajulu P \& Balasubramanian K 2000 Influence of streptozotocin-induced diabetes and insulin treatment on the pituitary-testicular axis during sexual maturation in rats. Experimental and Clinical Endocrinology and Diabetes 108 14-20. (https://doi.org/10.1055/s-0032-1329210)

Suthagar E, Soudamani S, Yuvaraj S, Ismail Khan A, Aruldhas MM \& Balasubramanian K 2009 Effects of streptozotocin (STZ)induced diabetes and insulin replacement on rat ventral prostate. Biomedicine \& Pharmacotherapy 63 43-50. (https://doi.org/10.1016/j. biopha.2008.01.002)

Tanaka T, Nagatani S, Bucholtz DC, Ohkura S, Tsukamura H, Maeda K \& Foster DL 2000 Central action of insulin regulates pulsatile luteinizing hormone secretion in the diabetic sheep model. Biology of Reproduction 62 1256-1261. (https://doi.org/10.1095/biolreprod62.5.1256)

Tartarin P, Moison D, Guibert E, Dupont J, Habert R, Rouiller-Fabre V, Frydman N, Pozzi S, Frydman R, Lecureuil C et al. 2012 Metformin exposure affects human and mouse fetal testicular cells. Human Reproduction 27 3304-3314. (https://doi.org/10.1093/humrep/des264)

Tavares RS, Portela JM, Sousa MI, Mota PC, Ramalho-Santos J \& Amaral S 2016 High glucose levels affect spermatogenesis: an in vitro approach. Reproduction, Fertility, and Development.

The Diabetes Control and Complications Trial Research Group 1993 The effect of intensive treatment of diabetes on the development and progression of long-term complications in insulin-dependent diabetes mellitus. New England Journal of Medicine 329 977-986. (https://doi. org/10.1056/nejm199309303291401)

Tesone M, de Souza Valle LB, Foglia VG \& Charreau EH 1976 Endocrine function of the testis in streptozotocin diabetic rats. Acta Physiologica Latino Americana 26 387-394.

Thomas K, Sung DY, Chen X, Thompson W, Chen YE, McCarrey J, Walker W \& Griswold M 2011 Developmental patterns of PPAR and RXR gene expression during spermatogenesis. Frontiers in Bioscience (Elite Edition) 3 1209-1220. (https://doi.org/10.2741/e324)

Thule PM \& Umpierrez G 2014 Sulfonylureas: a new look at old therapy. Current Diabetes Reports 14 473. (https://doi.org/10.1007/s11892-0140473-5)

Tommasini R 1975 Pharmacological activity of glipizide. Current Medical Research and Opinion 3 7-19. (https://doi. org/10.1185/03007997509111970)

Tremblay RR, Trottier L, Abele V, Nadeau A \& Gagnon P 1985 Effect of streptozotocin-induced diabetes on insulin binding 
parameters in adult rat testis. Andrologia 17 587-591. (https://doi. org/10.1111/j.1439-0272.1985.tb01722.x)

Trube G, Rorsman P \& Ohno-Shosaku T 1986 Opposite effects of tolbutamide and diazoxide on the ATP-dependent $\mathrm{K}+$ channel in mouse pancreatic beta-cells. Pflügers Archiv 407 493-499. (https://doi. org/10.1007/bf00657506)

Vanky E, Zahlsen K, Spigset O \& Carlsen SM 2005 Placental passage of metformin in women with polycystic ovary syndrome. Fertility and Sterility 83 1575-1578. (https://doi.org/10.1016/j.fertnstert.2004.11.051)

Verit A, Verit FF, Oncel H \& Ciftci H 2014 Is there any effect of insulin resistance on male reproductive system? Archivio Italiano di Urologia e Andrologia 86 5-8. (https://doi.org/10.4081/aiua.2014.1.5)

Vierhapper H, Nowotny P \& WaldhausI W 2003 Reduced production rates of testosterone and dihydrotestosterone in healthy men treated with rosiglitazone. Metabolism 52 230-232. (https://doi.org/10.1053/ meta.2003.50028)

Vignon F, Le Faou A, Montagnon D, Pradignac A, Cranz C, Winiszewsky P \& Pinget M 1991 Comparative study of semen in diabetic and healthy men. Diabete and Metabolisme 17 350-354.

Wajchenberg BL 2007 beta-Cell failure in diabetes and preservation by clinical treatment. Endocrine Reviews 28 187-218. (https://doi. org/10.1210/10.1210/er.2006-0038)

Wang L, Tian W, Uwais Z, Li G, Li H, Guan R, Gao Z \& Xin Z 2014 AGE-breaker ALT-711 plus insulin could restore erectile function in streptozocin-induced type 1 diabetic rats. Journal of Sexual Medicine $\mathbf{1 1}$ 1452-1462. (https://doi.org/10.1111/jsm.12533)

Wankeu-Nya M, Florea A, Balici S, Watcho P, Matei H \& Kamanyi A 2013 Dracaena arborea alleviates ultra-structural spermatogenic alterations in streptozotocin-induced diabetic rats. BMC Complementary and Alternative Medicine 13 71. (https://doi.org/10.1186/1472-6882-13-71) WHO (World Health Organization) 2016 Global Report on Diabetes.

Yamanaka M, Shirai M, Shiina H, Tanaka Y, Tsujimura A, Matsumiya K, Okuyama A \& Dahiya R 2003 Diabetes induced erectile dysfunction and apoptosis in penile crura are recovered by insulin treatment in rats. Journal of Urology 170 291-297. (https://doi.org/10.1097/01. ju.0000060564.31122.2a)

Yonezawa A, Ebiko M, Yoshizumi M, Ise SN, Watanabe C, Mizoguchi $\mathrm{H}$, Iwasaki M, Kimura Y \& Sakurada S 2009 Effects of insulin replacement on ejaculatory dysfunction in streptozotocin-induced diabetic rats. International Journal of Urology 16 208-211. (https://doi.org/10.1111/ j.1442-2042.2008.02214.x)

Young A 2005 Tissue expression and secretion of amylin. Advances in Pharmacology 52 19-45. (https://doi.org/10.1016/S10543589(05)52002-7)

Zhang J \& Liu F 2014 Tissue-specific insulin signaling in the regulation of metabolism and aging. IUBMB Life 66 485-495. (https://doi. org/10.1002/iub.1293)

Zhang E, Xu F, Liang H, Yan J, Xu H, Li Z, Wen X \& Weng J 2015 GLP1 receptor agonist exenatide attenuates the detrimental effects of obesity on inflammatory profile in testis and sperm quality in mice. American Journal of Reproductive Immunology 74 457-466. (https:// doi.org/10.1111/aji.12420)

Zhou G, Myers R, Li Y, Chen Y, Shen X, Fenyk-Melody J, Wu M, Ventre J, Doebber T, Fujii $\mathbf{N}$ et al. 2001 Role of AMP-activated protein kinase in mechanism of metformin action. Journal of Clinical Investigation 108 1167-1174. (https://doi.org/10.1172/JCl13505)

Received 26 June 2017

First decision 5 August 2017

Revised manuscript received 15 September 2017

Accepted 9 October 2017 